\title{
Diurnal cycle of summer precipitation over the Eastern Tibetan Plateau and surrounding regions simulated in a convection-permitting model
}

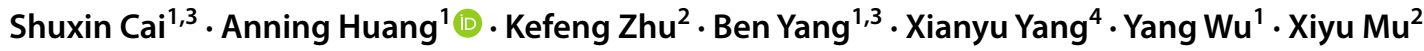

Received: 12 August 2020 / Accepted: 9 March 2021 / Published online: 23 March 2021

(c) The Author(s) 2021

\begin{abstract}
Based on the hourly gauge-satellite merged precipitation data with the spatial resolution of $0.1^{\circ} \times 0.1^{\circ}$ during $2013 \sim 2018$, we have evaluated the performance of the convection-permitting Weather Research and Forecasting model at Nanjing University (WRF_NJU) in forecasting the precipitation diurnal variation and the associated atmospheric circulation over the eastern Tibetan Plateau and its surrounding regions during summer. Results indicate that WRF_NJU model can well reproduce the diurnal cycle of the summer precipitation in terms of the diurnal peak time, duration and magnitude. In addition, the eastward propagation of rainfall systems with long duration along the eastern Tibetan Plateau (ETP) and its adjacent areas can also be properly captured. The WRF_NJU model can reasonably reproduce the relevant atmospheric circulation during summer as well. However, the model tends to underestimate the summer precipitation amount (PA) and precipitation frequency (PF) over most time of a day. Relatively larger biases in the occurring time and magnitude of PA and PF diurnal peaks can be noted over the ETP and Sichuan Basin. Further analysis suggests that the underestimation of PA over the ETP is attributed to the much lower moisture supply, weaker low-level southwesterly winds and less convective available potential energy (CAPE) in the WRF_NJU model than in ERA5. Over Sichuan Basin, the underestimated PA is related to the weaker upward motion, which is corresponding to the cold biases of surface air temperature in WRF_NJU. Findings of this study provide the basic model biases and may be helpful to further improve the model physical processes.
\end{abstract}

\section{Introduction}

The diurnal variation of precipitation can modify the temporal averaged energy budget of the earth's climate system (Dai et al. 2004; Chakraborty et al. 2008). Many previous studies have studied the characteristics, influence factors and propagation of rainfall diurnal cycles over different regions (Kishtawal et al. 2001; Zhou et al. 2008; Dai et al. 1999; Li et al. 2008; Yin et al. 2009; Chen et al. 2013; Yuan et al. 2010; Higgins et al. 1997; Wang et al. 2000; He et al. 2010). Revealing the spatial and temporal characteristics of rainfall diurnal variation not only helps us to understand the physical mechanism of precipitation and the formation of local climate but also offers us valuable information for evaluating the performance of models and identifying the physical sources of model errors.

Tibetan Plateau (TP) with an area of about 2.5 million $\mathrm{km}^{2}$ is the largest plateau in the world. Owing to its large and complicated terrain, it exerts great influence on local rainfall diurnal evolution through dynamical and thermal effects (Nan et al. 2009; Zhou et al. 2009; Wu et al. 2012). Precipitation over TP usually falls in summer $(60-70 \%$ of 
the annual total) and decreases from the southeastern part to the northwestern part (Wang et al. 2018). In summer, the precipitation often reaches its diurnal peak during late afternoon to midnight (midnight to early morning) over most TP and the downstream plains (such as the Sichuan Basin), respectively (Geng et al. 2007; Chen et al. 2009; Yu et al. 2009; Yin et al. 2009; Jin et al. 2013; Wu et al. 2018). Early studies have revealed the mechanisms of the formation and propagation of rainfall diurnal peaks over TP in summer. Mountain-valley breeze and convective activities induced by the favorable thermal and moist conditions can enhance the afternoon to midnight rainfall over TP (Yuan et al. 2011; Fujinami et al. 2005; Singh et al. 2009). In addition, the radiative cooling of the stratiform cloud top may trigger the precipitation over the lee side of TP during night (Yu et al. 2004). It is found that the precipitation shows obvious eastward phase delay of diurnal peak starting from TP, e.g., the diurnal peak time of rainfall is several hours later over Sichuan Basin than over TP (Jin et al. 2013; Zhang et al. 2019). The nocturnal precipitation over Sichuan Basin are attributed to several reasons, i.e. the unique topography and the heat flux provided by the underlying surface and the indirectly thermal lift of airflow and eastward convective systems from TP in the evening (Lu et al. 2003; Huang et al. 2010; Jin et al. 2013). Recently, Zhang et al. (2019) emphasized that the diurnal oscillation of boundary lowlevel jet plays a key role in modulating the diurnal cycles of precipitation in Sichuan Basin. Overall, the spatial distribution, diurnal cycle and propagation features of precipitation over and around TP are complicated and can exert potential influences on the climate and ecosystem of East Asia.

However, due to the complex terrain, harsh climate and scare field stations, it is difficult and challenging to study the detailed feature of precipitation diurnal cycle and related physical mechanisms over TP. Nowadays, high resolution satellite products are preferred to analyze the diurnal variation of precipitation with much more detailed structures (Wang et al. 2018; Wu et al. 2018; Chen et al. 2013, 2018; Zhao et al. 2020). While the satellite estimated rainfall products show relatively large biases over the TP (Huang et al. 2016). Fortunately, apart from the gauge records and satellite products, the development of high-resolution General Circulation Model (GCM) and Regional Climate Model (RCM) can present the continuous rainfall diurnal evolution and the related atmospheric circulations. Generally, the RCMs can reproduce more detailed features of precipitation and outperform the GCMs, particularly over the regions with complex terrain such as the TP (Hu et al. 2014; Jiang et al. 2015; Zhang et al. 2005; Shi et al. 2011; Wang et al. 2013). The most evident biases are the overestimation of rainfall in the southern slope of TP and the spurious rainfall center (Wang et al. 2018). The biases of simulation are significantly model dependent and mostly come from the improper horizontal resolution and the uncertainties in physical parameterization schemes (Yu et al. 2014; Kang et al. 2014; Wang et al. 2018; Yang et al. 2018, 2020). Revealing the model biases in simulating the rainfall diurnal cycle and the associated reasons are important aspects in model evaluation, which may be helpful to further improve the physical processes in models.

In recent years, the uncertainties in the physical parameterizations can be partially reduced by adopting convectionpermitting models (CPMs) with the horizontal resolution of $0.05^{\circ}$ or less, in which the convection parameterization is switched off. CPMs can well represent the deep convection and land-surface interactions (Prein et al. 2013, 2020; Rasmussen et al. 2014). Correspondingly, the forecasts of the life cycles of mesoscale convective systems, heating flux, snowpack, the intensity of hourly precipitation extremes and sub-daily precipitation variations are well improved (Clark et al. 2007; Fowle et al. 2003; Weisman et al. 1997; Weisman et al. 2008; Ban et al. 2014; Chan et al. 2014; Liu et al. 2016). So far, the CPMs, particularly the WRF model have been widely used in the weather and climatic evaluation studies of several regions around the world (Browning et al. 2007; Weisman et al. 2008; Kouadio et al. 2018; Chang et al. 2018; Prein et al. 2017; Scaff et al. 2020; Kramer et al. 2018). Relatively, under the influences of the summer monsoon, the convective systems and the land surface inhomogeneity over the vast area of TP, the performance of WRF_CPM models may differ from those in the previous studies. Therefore, evaluating and understanding the performance of the WRF_CPM model over TP is needed.

Previous studies have proven that the WRF model with convection-permitting resolution show good accuracy in simulating the seasonal or diurnal cycle of precipitation over TP (Maussion et al. 2011; Lin et al. 2018; Li et al. 2020a; Ou et al. 2020). Nevertheless, due to the expensive computing cost of CPMs, those published studies either have limited domain coverage or short period forecasts. None of them have systematically evaluated the performance of the realtime CPM models over the eastern TP and adjacent areas with a long period. Using 6-years real-time forecasts of the convective-permitting WRF model at Nanjing University (WRF_NJU), this study evaluates the predicted precipitation features over and around the TP in summer, which is the main rainy season with active meso-and micro-scale systems affected by the monsoonal circulation (Lin et al. 2014). Zhu et al. (2018) have shown that the WRF_NJU model performs better in predicting the precipitation diurnal variation, distribution and as well as intensity than other global forecasts over China region (e.g. the NCEP Global Forecasting System, the Japanese Meteorological Agency, and the European Centre for Medium-Range Weather Forecasts) in 2013 and 2014 over China. However, how well does the WRF_NJU model in producing the detailed climatic and diurnal features of rainfall over and around $\mathrm{TP}$ with much longer period have 
not been evaluated yet. What are the main factors causing the precipitation forecast bias over complex terrain have not been well indicated. To answer such questions may be helpful to further improve the model physics.

The rest of this paper is organized as follows: The observation and forecast data are given in Sect. 2. In Sect. 3, the summer mean and the diurnal cycle of precipitation from the observation and the WRF_NJU model forecast product will be systematically compared. In Sect. 4, the possible reasons related to the modeled precipitation biases are presented. Finally, we give the summary and discussions in Sect. 5.

\section{Data and methodology}

\subsection{The observation data and WRF_NJU model forecast product}

The data used in this study are listed as follows:

(1) The gauge-satellite merged precipitation data combines quality-controlled hourly surface rainfall records at more than thirty thousand automatic weather stations with the precipitation product derived from the Climate Prediction Center's morphing rainfall estimates (CMORPH, hereafter; Joyce et al. 2004), which are available at http://data.cma.cn/data/cdcdetail/dataC ode/SEVP_CLI_CHN_MERGE_CMP_PRE_HOUR_ GRID_0.10.html. The CMORPH precipitation product is firstly corrected for the biases via matching probability density function with those of the rain-gauge measurements (Yu et al. 2013). Afterwards, the corrected CMORPH dataset is merged with the rain-gauge records by using the optimal interpolation method (Shen et al. 2014). This data has both the advantages of the field station records and the satellite estimated precipitation. Compared to the limited distributed raingauge measurements or the Tropical Rainfall Measuring Mission (TRMM 3B42 dataset, 3-h, $0.25^{\circ} \times 0.25^{\circ}$ ), this gauge-satellite merged precipitation product is able to present much more detailed rainfall characteristics (Wu et al. 2018; Li et al. 2020a). Shen et al. (2013, 2014) pointed that this gauge-satellite merged precipitation data has much smaller root mean square errors and systematic or random biases compared with the automatic weather stations and CMORPH data. In recent years, this gauge-satellite merged precipitation data has been proven to be reliable for warm-season and annual precipitation research over China, including the TP (Shen et al. 2010; Ji et al. 2017; Wu et al. 2018; Li et al. 2020a, b; Zhao et al. 2020).

(2) The forecast data was produced by the WRF_NJU model based on the WRF-ARW model Version 3.3.1
(Skamarock et al. 2005) which was run real-time with $4 \mathrm{~km}$ grid spacing during summer since 2013 (Zhu et al. 2016; Zhu et al. 2018; Xue et al. 2018; Zhang et al. 2019). The model domain of WRF_NJU model covers the entire China (Fig. 1). It has $1408 \times 1080$ horizontal grid points and 50 vertical levels. The $48 \mathrm{~h}$ forecasts are produced twice daily at 00:00 and 12:00 UTC with the initial and lateral boundary conditions derived from the 3 hourly NCEP Global Forecast System real-time forecasts. To avoid the initial spin-up period, we used the results with the forecast period of $12 \sim 36 \mathrm{~h}$ predicted by WRF_NJU model initialized at 12:00 UTC to obtain $24 \mathrm{~h}$ predictions and to investigate the precipitation diurnal cycle issues. In this study, the physical parameterization schemes used in WRF_NJU model include the Morrison 2-moment microphysics (Morrison et al. 2005), the Asymmetrical Convective Model version 2 (ACM2) planetary boundary layer scheme (Pleim 2007), the Pleim-Xiu land surface and surface layer schemes (Pleim 2006), and the CAM short- and long-wave radiation schemes (Collins et al. 2004). The cumulus parameterization scheme is turned off to conduct convection permitting forecast. Details of the model configuration are listed in Table 1. The WRF_NJU model shares the same source code as the official WRF version. But the configurations of WRF_ NJU model are specially tuned for the heavy rainfall prediction in China (Zhu et al. 2016). In general, in the east of $100^{\circ} \mathrm{E}$ (mainly outside TP), the WRF_NJU well reproduces the spatial distribution and diurnal variation of precipitation (Zhu et al. 2018).

(3) The ERA5 hourly reanalysis data include the zonal wind $(u)$, meridional wind $(v)$, vertical velocity $(\omega)$, temperature (T) and specific humidity (q) from 1000 to $100 \mathrm{hPa}$ with the horizontal resolution of $0.25^{\circ}$ (available at https://www.ecmwf.int/en/forecasts/datasets/ reanalysis-datasets/era5). The ERA5 is the next generation of ERA-Interim which is now based on a hybrid incremental 4D-Var system. It incorporates 10 years of $\mathrm{R} \& \mathrm{D}$ for all its components (atmosphere, land, ocean, observation operators and additional observations) as well as improvements in the data assimilation methodology (Bonavita et al. 2016; Hersbach et al. 2020). Studies have shown that ERA5 can well capture the physical characteristics of the upper-air and surface layer (Randel et al. 2016; Maycock et al. 2018; Belmonte Rivas and Stoffelen 2019; Olauson 2018; Kalverla et al. 2019). Many studies (e.g., Zhang et al. 2013; Gao et al. 2014; Li et al. 2020a; Yue et al. 2020) have already used the ERA-Interim or ERA5 reanalysis to evaluate the model performance over the TP. Verification using independent sounding observations showed that ERA-Interim (Dee et al. 2011) matches 
Fig. 1 Spatial distribution of terrain height over the Tibetan Plateau and its surrounding regions (shaded) in the model. The thick black squares sketch the sub-regions mentioned in Sect. 3. (sub-region 1: the ETP; sub-region 2: the Sichuan Basin; sub-region 3: the Yunnan-Guizhou Plateau)

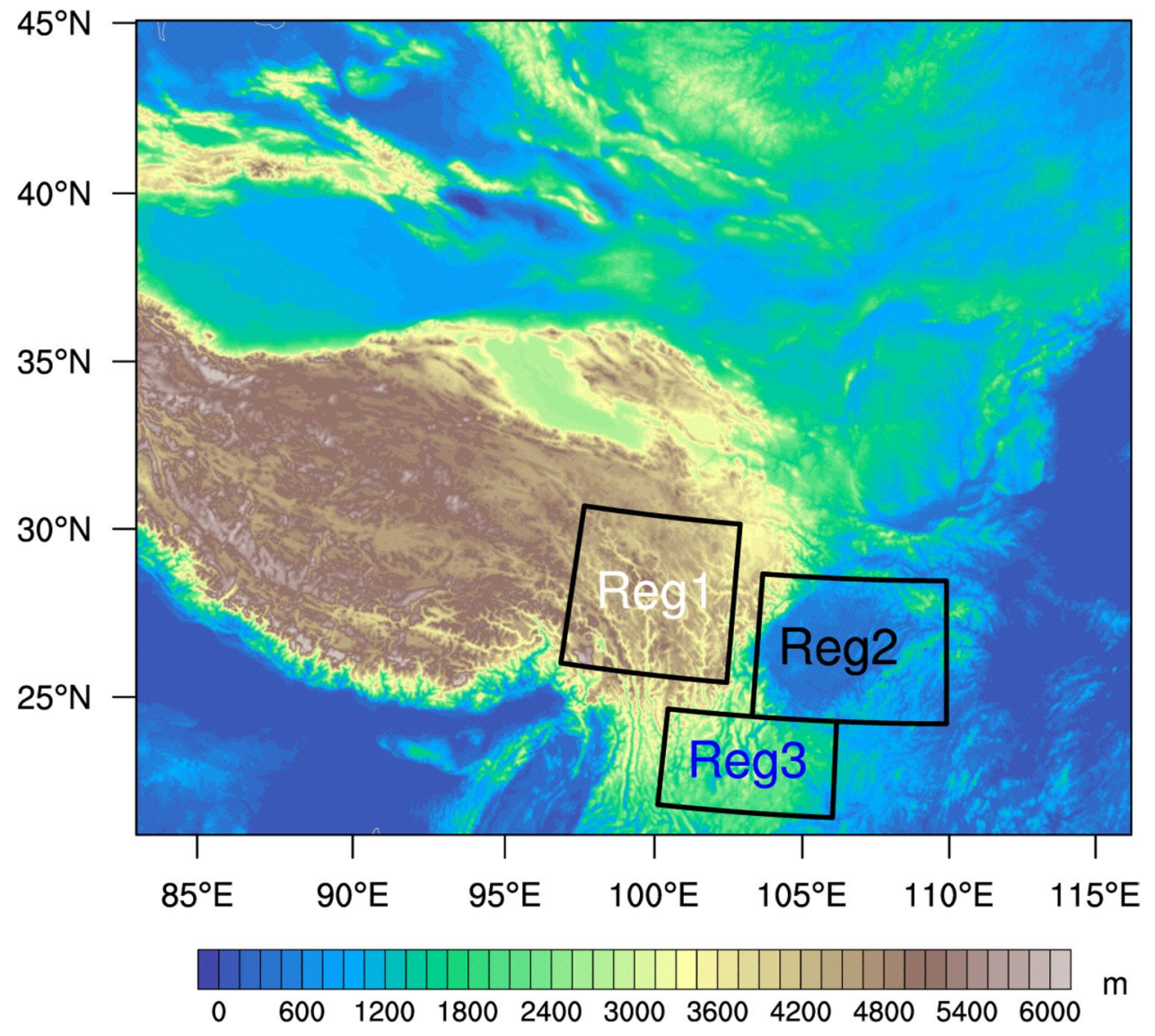

Table 1 WRF_NJU model configuration

\begin{tabular}{ll}
\hline Map and resolution settings & \\
\hline Map projection & Lambert \\
Horizontal grid spacing & $4000 \mathrm{~m}$ \\
Vertical layers & 50 levels \\
Staggered grid points & $1408 \times 1080$ \\
Initial and lateral boundary conditions & NCEP GFS real-time forecast (3-hourly, $\left.0.25^{\circ} \times 0.25^{\circ}\right)$ \\
Timing & \\
Staring hour & $00: 00$ UTC, 12:00 UTC (12:00 UTC is selected) \\
Forecasting period & $48 \mathrm{~h}(12-36$ h are selected) \\
Time step & $25 \mathrm{~s}$ \\
Physical parameterization schemes & \\
Long-wave radiation & CAM scheme (Collins et al. 2004) \\
Short-wave radiation & CAM scheme (Collins et al. 2004) \\
Land surface & Pleim-Xiu (Pleim et al. 1995) \\
Planetary boundary & Asymmetrical Convective Model version 2 (ACM2, \\
Microphysics & Pleim et al. 2007) \\
\hline
\end{tabular}

the observation very well over the TP, especially at low level (Bao and Zhang, 2013). We have also calculated the root mean square errors at 500-200 hPa (not shown) against 5 sounding observations over $\operatorname{ETP}\left(29 \sim 34^{\circ} \mathrm{N}\right.$, $\left.96 \sim 102^{\circ} \mathrm{E}\right)$. The root mean square errors of $\mathrm{u}$ and $\mathrm{v}$ wind components, temperature, water vapor mixing ratio of ERA5 are smaller than $1.4 \mathrm{~ms}^{-1}, 0.8 \mathrm{~K}$ and 0.5 $\mathrm{g} \mathrm{kg}^{-1}$, respectively. Meanwhile, the observation error for corresponding variables of radiosondes are nearly $2 \mathrm{~ms}^{-1}, 1 \mathrm{~K}, 1 \mathrm{~g} \mathrm{~kg}^{-1}$, respectively. The current ERA5 
reanalysis is reliable and can be used for model evaluation.

\subsection{Analysis methods}

In this study, we stipulate $0.1 \mathrm{~mm} \mathrm{~h}^{-1}$ for each hour of one day (00:00 23:00 BJT) at every grid point as a threshold of valid precipitation. Following Zhou et al. (2008) and Wu et al. (2018), the summer average of PA is calculated as the valid accumulated precipitation divided by the total hours of all summer months (June-August) during 2013-2018, PF is the percentage of the total precipitating hours to the total hours in summer, and precipitation intensity (PI) is the accumulated precipitation divided by the total precipitating hours $(\mathrm{PI}=\mathrm{PA} / \mathrm{PF})$.

In addition, following Yu et al. (2007), the rainfall duration is defined as the number of hours from the beginning to the end of a rainfall event with no intervals that have rainfall amount below $0.1 \mathrm{~mm} \mathrm{~h}^{-1}$. Then, the precipitation is divided into short-duration $(\leq 3 \mathrm{~h})$ precipitation, which is mostly triggered by strong solar heating with the diurnal maximum rainfall around late afternoon, and longduration ( $\geq 6 \mathrm{~h}$ ) precipitation that is mainly caused by the organized rainfall systems closely related to the large scale circulation rather than isolated convection and generally shows midnight to early morning peak (Yu et al. 2007; Li et al. 2008). The standardized PA, PF and PI are derived according to the formula $\mathrm{D}(\mathrm{h})=(\mathrm{R}(\mathrm{h})-\mathrm{Rm}) / \mathrm{Rm}(\mathrm{Yu}$ et al. 2007), in which $h$ is the hour of a day and varies from 00:00 to 23:00 Beijing time (BJT). R is the hourly PA, PF and PI, and $\mathrm{Rm}$ is the daily mean of PA, PF and PI.

To evaluate the amplitude and pattern of variability between the observation and simulation quantitatively, we adopt the Taylor score (Taylor 2001) given by

$S=\frac{4(1+\mathrm{R})}{\left(\sigma+\frac{1}{\sigma}\right)^{2}\left(1+R_{0}\right)}$,

where $\mathrm{R}$ is the pattern correlation (PC) between the observation and model prediction, $\sigma$ is the ratio of spatial standard deviation of the model prediction to that of the observation. $\mathrm{R}_{0}$ is an available maximal correlation which is set to 1 . The forecast skill is high as $S$ approaches 1 . On the contrary, as the correlation becomes negative or $\sigma$ towards 0 or infinity, the skill is bad.

Given that the calculated PF and PI are sensitive to the spatial resolution (Chen et al. 2018), we apply the local area averaging method to interpolate both the model data and the reanalysis data onto the grids of gauge-satellite merged precipitation product with the horizontal resolution of $0.1^{\circ} \times 0.1^{\circ}$.
Additionally, the moist static energy (MSE) which demotes the total static energy of the atmosphere is used to indicate the instability associated with rainfall (Neupane and Cook 2013; Li et al. 2018). MSE is divided into dry static energy and latent static energy and given by:

$M S E=D S E+L S E$,

$D S E=C_{p} \times T+g \times z$,

$L S E=L_{v} \times q$,

where $C_{p}$ and $L_{v}$ is the specific heat of dry air at constant pressure and the latent heat of vaporization of water in Eq. (3) and Eq. (4), respectively. $T$ is the air temperature, $q$ is the specific humidity, $g \times z$ is the geopotential. When the profile of the MSE decreases with the altitude, the atmosphere is unstable.

\section{The predicted precipitation in WRF_NJU}

\subsection{Spatial distribution of the PA, PF and PI in summer}

Figure 2 gives the observed and modeled summer mean PA, PF and PI over and around the ETP. In observation, the summer mean observed PA (Fig. 2a) increases from northwest to southeast and reaches a maximum $\left(0.5 \mathrm{~mm} \mathrm{~h}^{-1}\right)$ at the margin of the western Sichuan Basin and the north Yunnan-Guizhou Plateau. The spatial pattern of the observed PF (Fig. 2b) is similar to PA, which is consistent with the previous findings (Ji et al. 2017; Guo et al. 2019). The largest PF appears over the southwest Sichuan Basin and north of Yunnan-Guizhou Plateau with the maximum value of $21 \%$. In Fig. 2c, the observed PI decreases from the Sichuan Basin to the ETP with the largest PI $\left(\sim 2.2 \mathrm{~mm} \mathrm{~h}^{-1}\right)$ located over the south slope of the ETP.

Overall, the model can well capture the general spatial features of the summer precipitation over the entire domain. The pattern correlations between the prediction and observation are $0.87,0.89,0.92$ for PA, PF and PI (Fig. 2d-f), respectively. However, PA and PF are evidently underestimated over the ETP, the Sichuan Basin and Yunnan-Guizhou Plateau (Fig. 2d, e). Compared to PA and PF, the model shows better agreements in the magnitude of PI over most regions although some overestimation is noted over the southeast corner of the study domain.

The Taylor score (Eq. 1) is used to quantify the model performance of the model in reproducing the summer precipitation over the complicated terrains. We divide the study area into three sub-regions according to their characteristics and rainfall features. The sub-regions are the 
(a)Obs

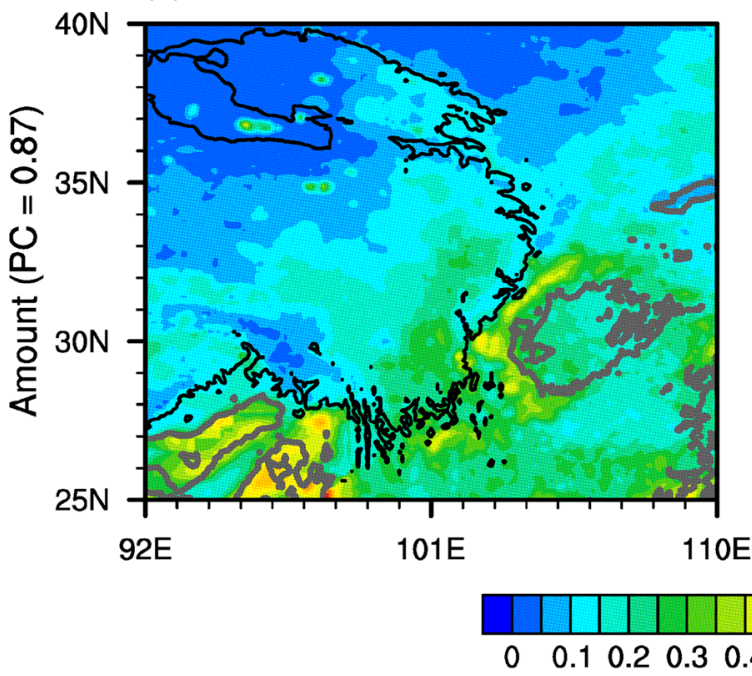

(b)Obs

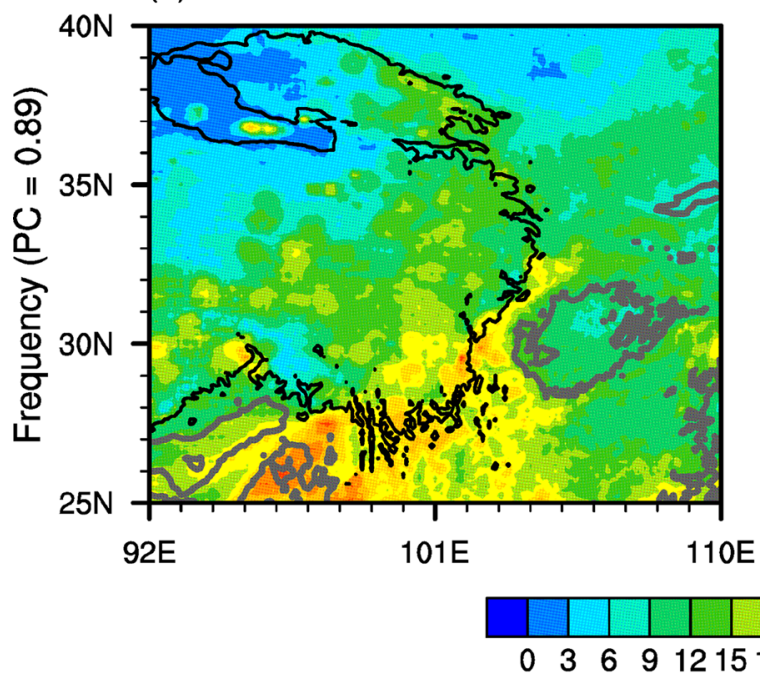

(c)Obs

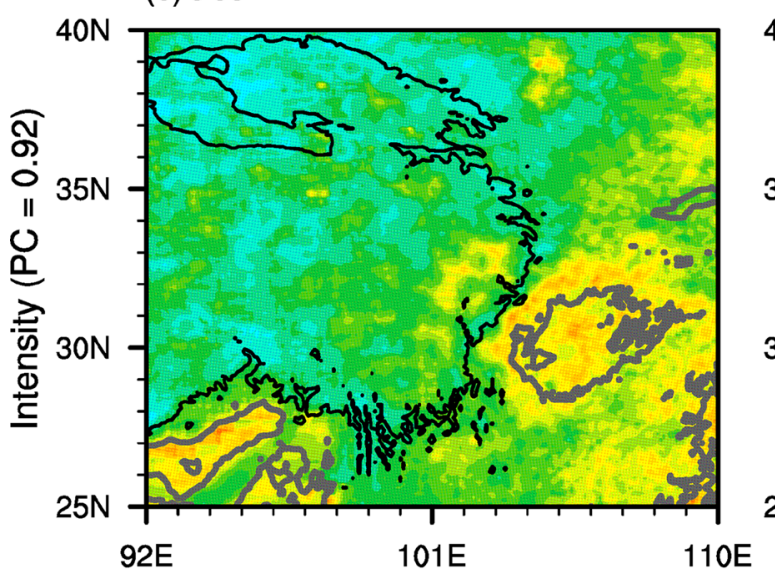

(d)WRF_NJU

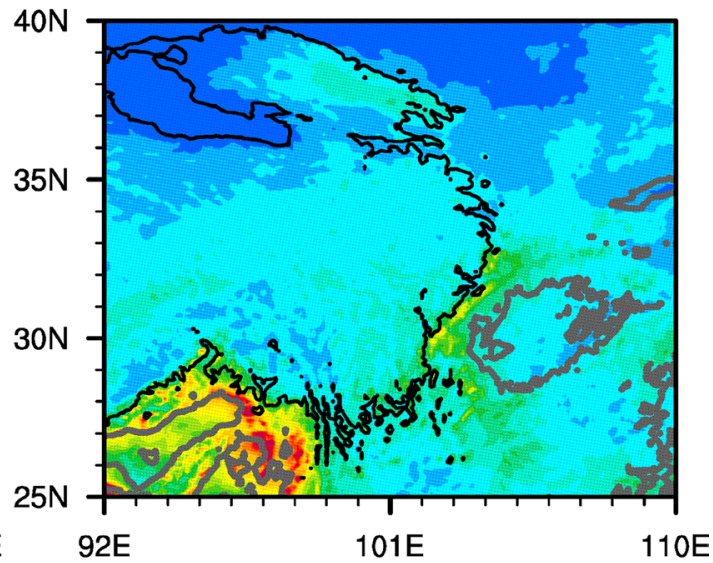

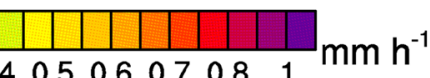

(e)WRF_NJU

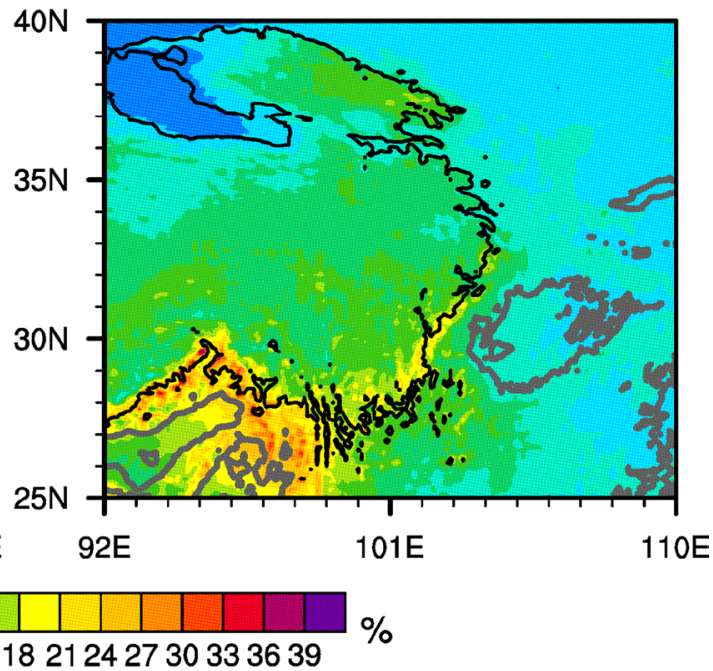

(f)WRF_NJU

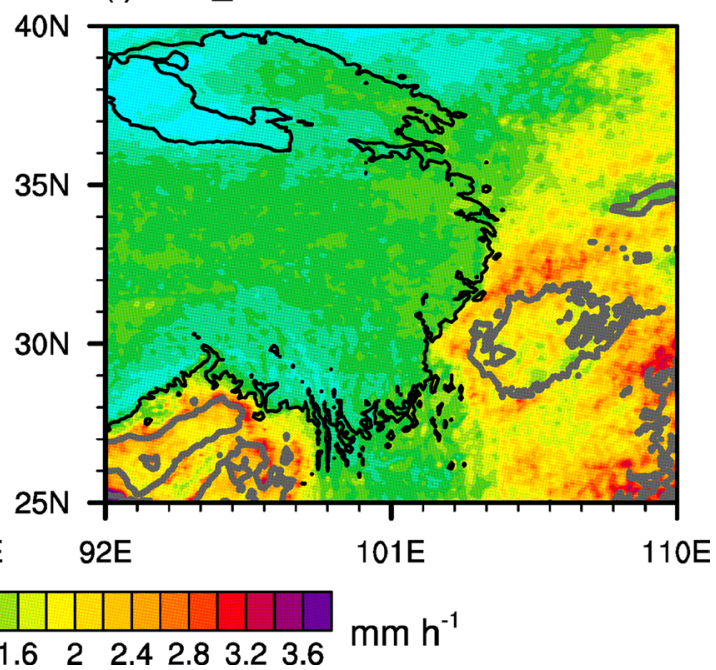

Fig. 2 The spatial distribution of the observed and WRF_NJU predicted summer mean PA, PF and PI averaged over 2013 2018. The black (gray) lines denote the terrain height of $3000(500) \mathrm{m}$ 
ETP (sub-region 1), the Sichuan Basin (sub-region 2) and the Yunnan-Guizhou Plateau (sub-region 3), respectively (Fig. 1). As indicated in Fig. 3, the Taylor scores of PA and PF (Fig. 3a, b) all exceed 0.6 in the three sub-regions (Fig. 3a), suggesting that the model can well reproduce the pattern and magnitude of the observed precipitation variability. The Sichuan Basin shows the highest scores among the three sub-regions. Based on Ji et al. (2017), we sort the rainfall into four categories as follows: $0.1 \sim 0.25 \mathrm{~mm} \mathrm{~h}^{-1}$, $0.25 \sim 1 \mathrm{~mm} \mathrm{~h}^{-1}, 1 \sim 4 \mathrm{~mm} \mathrm{~h}^{-1}$ and $\geq 4 \mathrm{~mm} \mathrm{~h}^{-1}$. Figure 4 displays the model biases of PA and PF for the total rainfall and rainfall at each intensity category. From Fig. 4a, b, the model errors in PA and PF over the ETP are mainly contributed by the largely underestimated rainfall of $1 \sim 4 \mathrm{~mm} \mathrm{~h}^{-1}$. In Sichuan Basin and Yunnan-Guizhou Plateau, the underestimated total PA and PF are also mainly attributed to the

\section{TS scores}
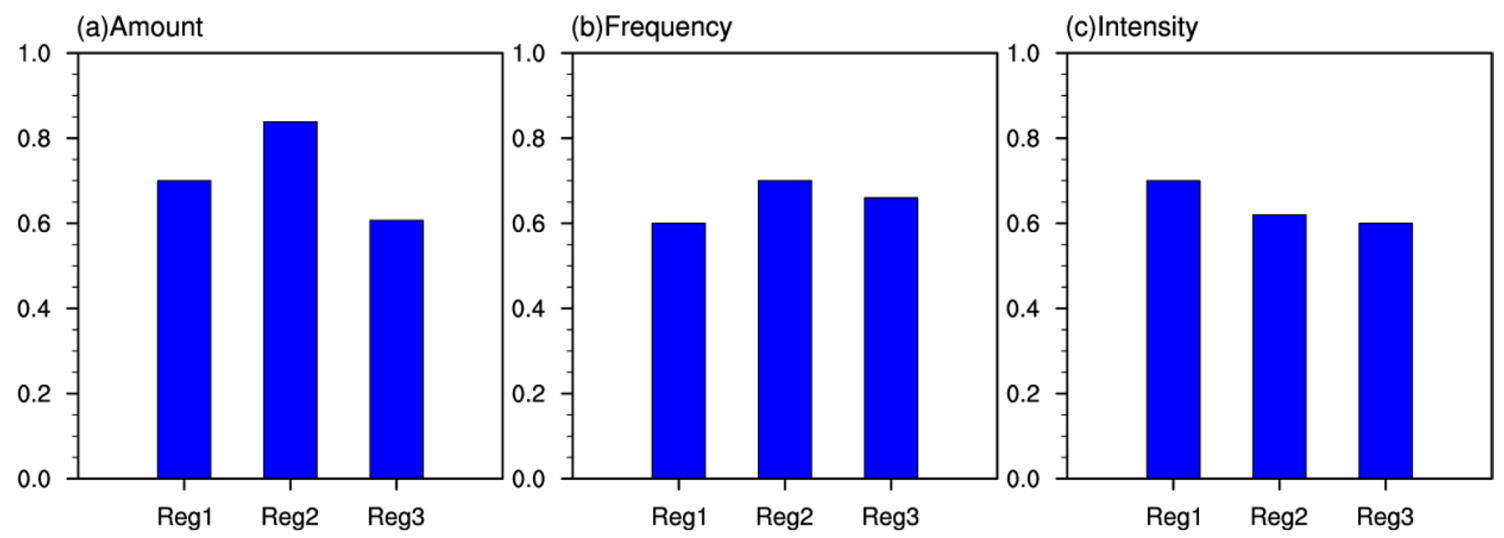

Fig. 3 Taylor scores of the predicted summer mean PA, PF and PI averaged over 2013 2018 in each sub-region
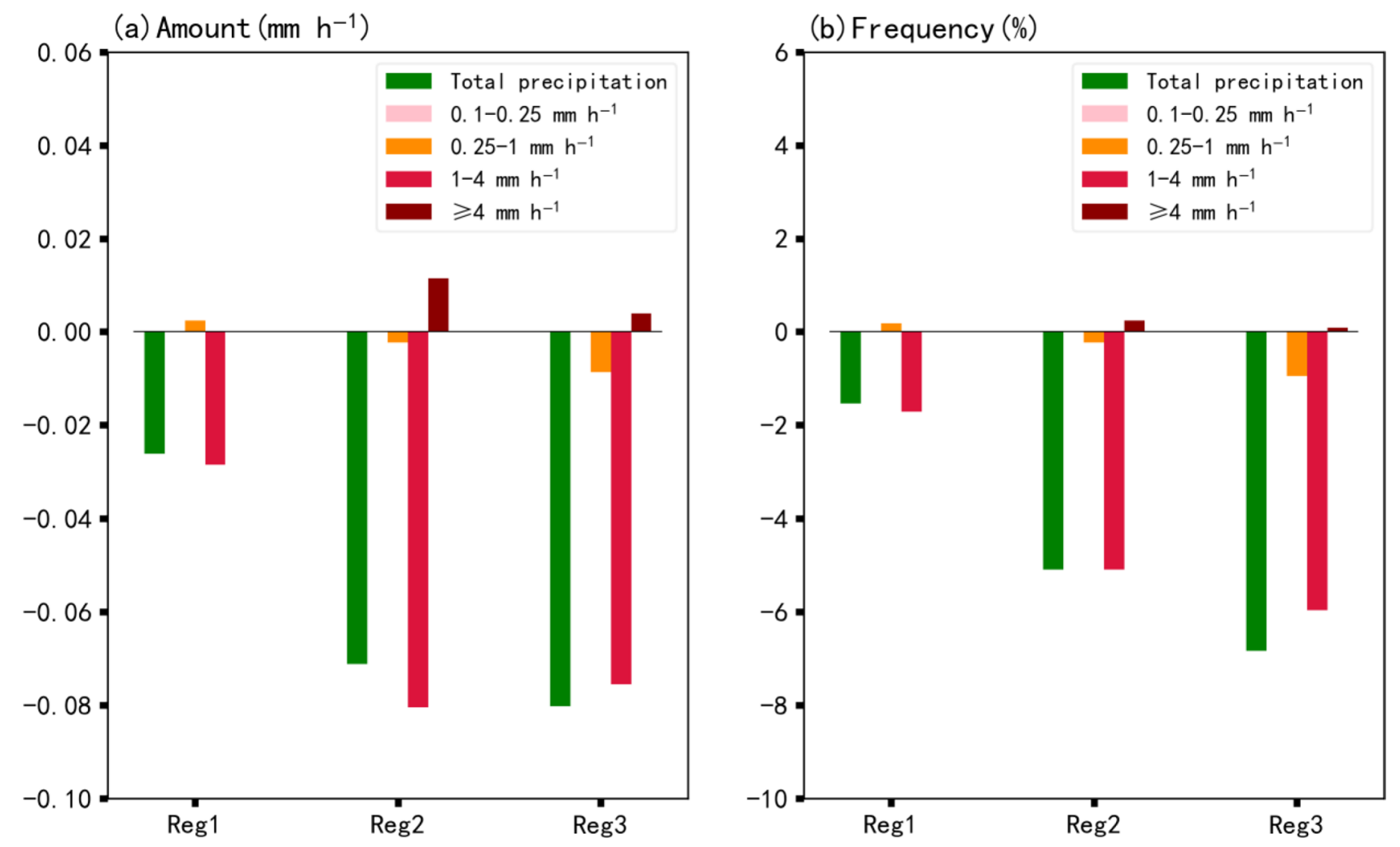

Fig. 4 Biases of the WFR_NJU predicted summer mean PA and PF with different rainfall categories averaged over $2013 \sim 2018$ against the observation regionally averaged over each sub-region 
underestimated rain with the intensity of $1 \sim 4 \mathrm{~mm} \mathrm{~h}^{-1}$. Moreover, among the three sub-regions, the model biases in the total precipitation vary regionally, with the largest (lowest) bias of around $-0.08(-0.025) \mathrm{mm} \mathrm{h}^{-1}$ for the total PA and $-7 \%(-1.8 \%)$ for the total PF over the Yunnan-Guizhou Plateau (ETP), respectively.

\subsection{Diurnal variations of the PA, PF and PI in summer}

Since the topography varies significantly from the ETP to Sichuan Basin, the diurnal cycles of PA, PF and PI show distinct regional differences (Wu et al. 2018). Figure 5 shows the spatial distribution of the diurnal peak times of PA, PF and PI. Over ETP, the observed PA and PF diurnal peaks mostly appear around 20:00 BJT-02:00 BJT (Fig. 5a, b), which is consistent with previous studies (Jin et al. 2013; Chen et al. 2013; Wu et al. 2018). These late afternoon to midnight rainfall diurnal peaks are associated with the solar heating and the accelerated low-level southwesterly flow (Bao et al. 2011; Chen et al. 2010; Ueno et al. 2011), strengthened water vapor transport, and upward movement of mountain-plain solenoid (Bao et al. 2011; Jin et al. 2013). Over Sichuan Basin, the PA and PF diurnal peaks mainly occur between midnight (02:00 BJT) and early morning (about 04:00 BJT), several hours later than the diurnal peak time of precipitation over the ETP (Fig. 5a, b). This nocturnal rainfall is often called as "Bashan nocturnal rainfall" and it accounts for nearly $70 \%$ of the total rainfall (Zheng et al. 2016). The model well depicts the distribution of the diurnal peak times of PA and PF over most areas (Fig. 5c, d). However, the predicted PA and PF diurnal peaks over the ETP occurs about 1-2 $\mathrm{h}$ earlier than that in the observation (Fig. 5c, d).

Figure 6 further gives the detailed diurnal evolutions of predicted and observed PA, PF and PI over each subregion. Over the ETP, the observed PA presents the diurnal peak occurring at 20:00 BJT with the magnitude about $0.27 \mathrm{~mm} \mathrm{~h}^{-1}$ (Fig. 6a). The minimum PA appears around noon with the value of $0.05 \mathrm{~mm} \mathrm{~h}^{-1}$. The PF shows similar diurnal phase to PA (Fig. 6b). While the PI (Fig. 6c) has one obvious peak at midnight (00:00 BJT). Over the Sichuan Basin (sub-region 2), the observed diurnal cycle of PA exhibits bimodal distribution (Fig. 6d). The primary diurnal peak occurs at 04:00 BJT with a magnitude of $0.32 \mathrm{~mm} \mathrm{~h}^{-1}$, and the secondary peak appears around 17:00 BJT with the intensity of $0.21 \mathrm{~mm} \mathrm{~h}^{-1}$. This secondary afternoon peak is probably caused by the local mountain heating in summer (Jin et al. 2013). The observed PF in Sichuan Basin also exhibits two diurnal peaks with the predominant peak (about
Fig. 5 Spatial distribution of the diurnal peak timings of summer mean PA and PF during 2013 2018 from observation and WRF_NJU prediction. The black (gray) lines denote the terrain height of 3000 (500) $\mathrm{m}$ and the black boxes denote the subregion 1 (ETP) and sub-region 2 (Sichuan Basin)
(a)Obs

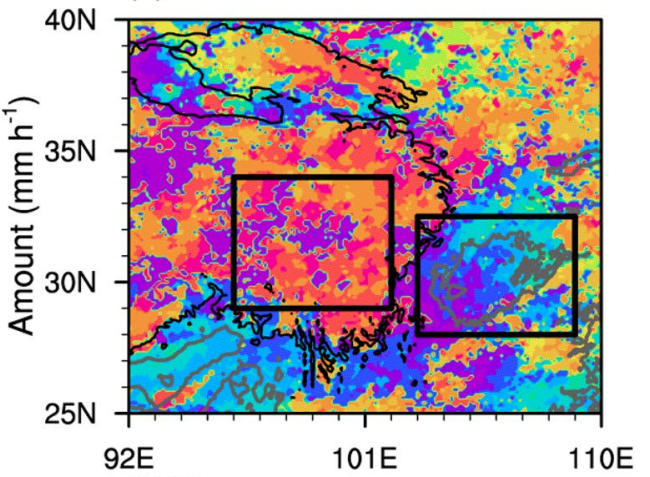

(b)Obs

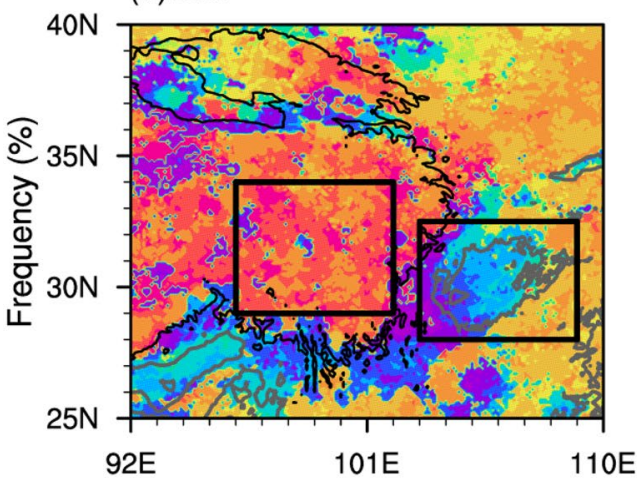

(c)WRF_NJU

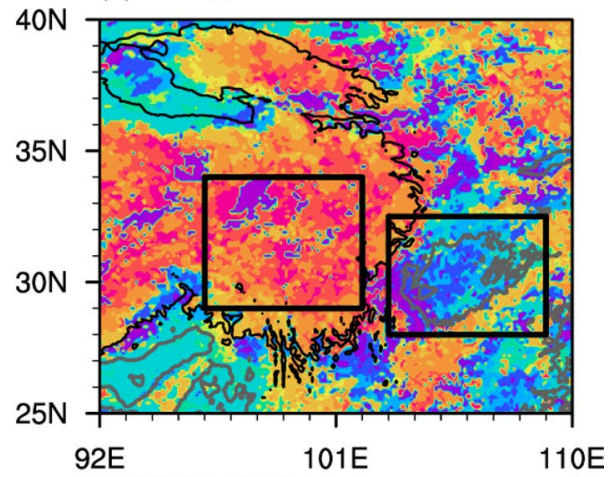

(d)WRF_NJU

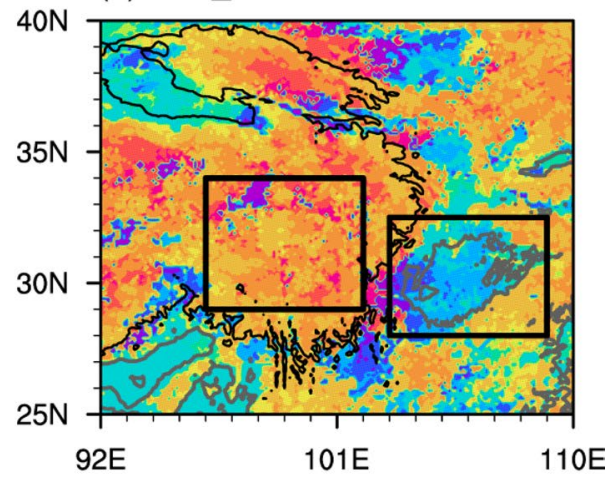

$\begin{array}{lllllllllll}2 & 4 & 6 & 8 & 10 & 12 & 14 & 16 & 18 & 20 & 22\end{array}$ 

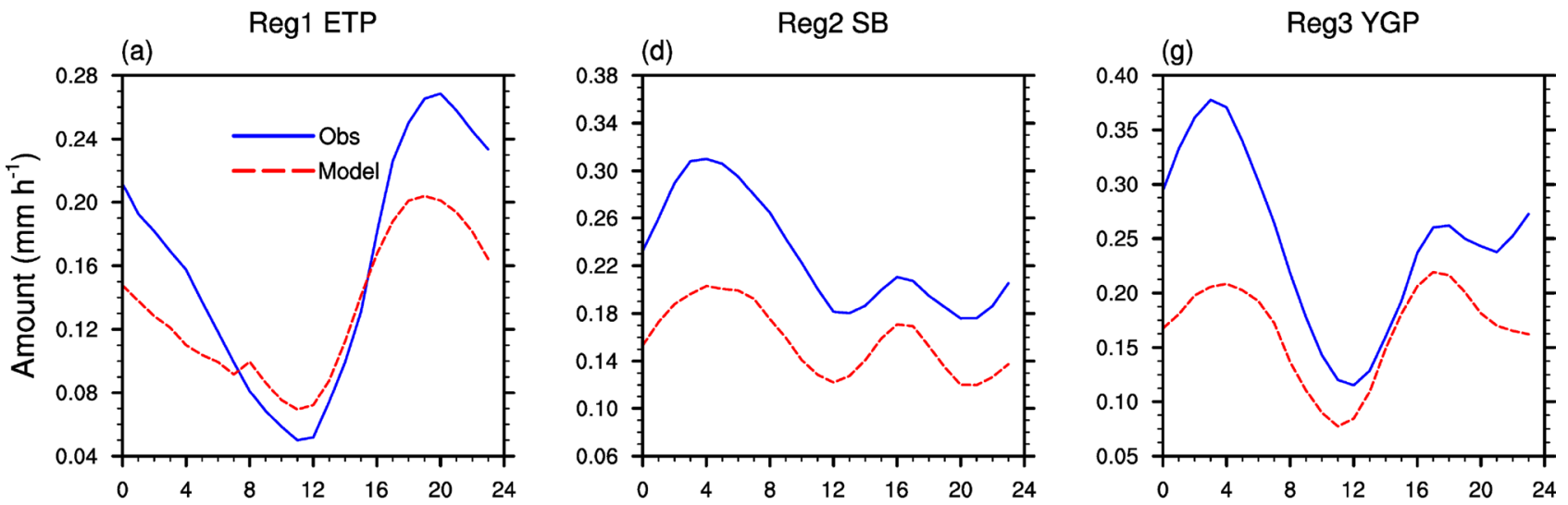

(b)
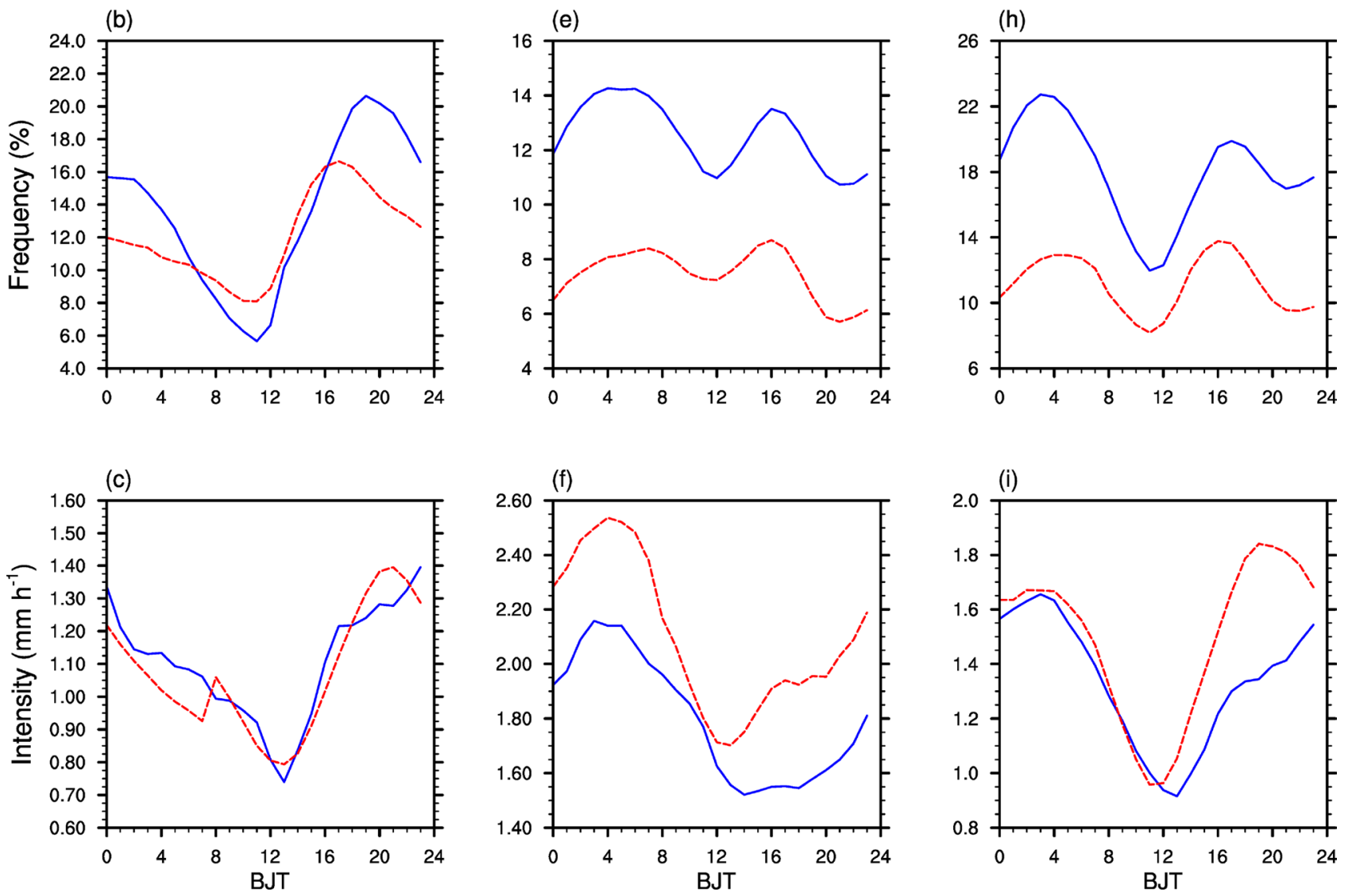

Fig. 6 Diurnal variations of the observed and predicted summer mean PA, PF and PI averaged over $2013 \sim 2018$ in each sub-region

$14.5 \%$ ) around 06:00 BJT and the secondary peak (about $13 \%$ ) at 16:00 BJT (Fig. 6e). Differently, the observed PI over the Sichuan Basin shows only one diurnal peak with the intensity of $2.19 \mathrm{~mm} \mathrm{~h}^{-1}$ around 04:00 BJT (Fig. 6f). The diurnal phases of the observed PA, PF and PI over the Sichuan Basin are in good agreement with the results of Jin et al. (2013). Both the observed PA and PF in Fig. 6g, h (PI in Fig. 6i) over the Yunnan-Guizhou Plateau show double diurnal peaks with a predominant peak at about 04:00 BJT and a secondary peak near 18:00 BJT (shows one diurnal peak around 04:00 BJT), similar to the situation over the Sichuan Basin (Fig. 6d, f).

The WRF_NJU model can well reproduce the overall diurnal phase of the precipitation over each sub-region despite some obvious biases in magnitudes (Fig. 6). As shown in Fig. 6a, b, the model can well reproduce the two diurnal peaks of PA and PF over the ETP, but the predicted PF shows a primary peak around 17:00 BJT, which is about 
$3 \mathrm{~h}$ earlier than that in the observation (Fig. 6b). Meanwhile, PA and PF over the ETP are much more largely underestimated by the model, particularly during nighttime $(18: 00$ $\mathrm{BJT} \sim 06: 00 \mathrm{BJT})$. In a word, the underestimated PF and PI contribute to the underestimation of PA over the ETP at most nighttime hours.

The WRF_NJU model can well reproduce the two diurnal peaks of PA and PF over Sichuan Basin (Fig. 6d, e). However, the model tends to underestimate the PA and PF at all hours of a day. Compared to PA and PF, the predicted PI shows much better agreements with the observation over the Sichuan Basin but with the diurnal peak occurring 1-2 $\mathrm{h}$ later than the observation (Fig. 6f). As a whole, the underestimation of PA over the Sichuan Basin is largely determined by the underestimated PF at all hours of a day. Similar situations can be found over the Yunnan-Guizhou Plateau (Fig. 6g, h), except that the predicted PI diurnal peak happens bout 6-7 h earlier than the observation (Fig. 6i).

Overall, the WRF_NJU model can well reproduce the diurnal phases of PA, PF and PI but considerably underestimates the magnitudes of the diurnal peaks for PA and PF over the Sichuan Basin and Yunnan-Guizhou Plateau in summer. It is notable that the model tends to underestimate PA and PF over the ETP during nighttime. The underestimation of PA over the Sichuan Basin and Yunnan-Guizhou Plateau (ETP) at most hours of a day is mainly attributed to the underestimated PF (both PF and PI) in the model.

\subsection{Precipitation with different duration time}

Figure 7 presents the spatial distributions of the contributions of long- and short-duration PA to the total PA from the observation and model prediction, as well as their differences in summer. The PA with long duration contributes more than $60 \%$ to the total PA in the observation over the southeast part of the study region where the terrain heights are generally below $3000 \mathrm{~m}$ (Fig. 7a). In contrast, more than $80 \%$ of the observed total PA is contributed by the shortduration PA in the northwestern TP in summer (Fig. 7b). The model well reproduces the contributions of short- and longduration PA to the total PA over the study region (Fig. 7c, d), but underestimates (overestimates) the contributions of the short-duration (long-duration) PA to the total PA up to $8 \%$ over most areas of the ETP (Fig. 7e, f). The reasons for the short- and long-duration PA differences between the model and observation will be discussed in the following sections.

The distribution of long- and short duration PA are also examined in Fig. 8. It is clearly shown that both long- and short-duration PA decrease from southeast to northwest over the study domain with large PA centers located along the eastern slope of TP (Fig. 8a, b). The short-duration PA is weaker (larger) than the long-duration PA over most southeast parts of the study area especially over the Sichuan Basin (ETP)
(Fig. 8a, b). The predicted long- and short-duration PA show very similar spatial patterns with the observation (Fig. 8c, d). However, relatively larger underestimation of short-duration PA can be noted over most ETP (Fig. 8f), which is corresponding to the slightly smaller contribution of short-duration PA in Fig. 7f. This underestimation of short-duration PA is related to the weaker convective activities in the model over the ETP. Also, the model underestimates both the long- and shortduration PA over the Sichuan Basin and Yunnan-Guizhou Plateau compared to the observation (Fig. 8e, f), which may be related to the relatively weaker background circulation or upward motion in the model shown in the following section.

To inspect the model performance in reproducing the eastward propagation of rainfall diurnal phases from the ETP to its downstream, the total PA and the PA with different duration meridionally averaged along $28^{\circ} \sim 40^{\circ} \mathrm{N}$ are presented in Fig. 9. As shown in Fig. 9a, the total PA in observation exhibits one diurnal peak from late afternoon to evening over the ETP along $96^{\circ} \sim 103^{\circ} \mathrm{E}$ and two diurnal peaks over the areas east to $103^{\circ} \mathrm{E}$ with a primary nocturnal peak resulting from long-duration rainfall and a secondary afternoon peak due to the short-duration rainfall (Wu et al. 2018). The precipitation is usually originated from the convective systems on the eastern slope of the plateau and moves eastward by the effects of southwesterly flow, the mountain-plain circulation, and convective instability (Carbone et al. 2002; Bao et al. 2011; Tian et al. 2005; Jiang et al. 2017; Huang et al. 2010). The PA with long duration displays distinct evening to midnight peak over the areas along $96 \sim 103^{\circ} \mathrm{E}$ and midnight to early morning peak over the regions along $103^{\circ} \sim 110^{\circ} \mathrm{E}$ (Fig. 9b). However, the diurnal peak of PA with short duration emerges between 15:00 BJT to 21:00 BJT along $96^{\circ} \sim 110^{\circ} \mathrm{E}$ without any propagation (Fig. 9c). Apparently, the eastward delayed diurnal phase of total PA between 16:00 BJT 04:00 BJT from the ETP to the Sichuan Basin and its downstream is mainly caused by the propagation of long duration precipitation (Wu et al. 2018).

Obviously, the WRF_NJU model well reproduces the timelongitude distribution of the total PA, and the long- and shortduration PA (Fig. 9d-f), particularly the eastward propagation of diurnal phase of rainfall with long duration starting from $103^{\circ} \mathrm{E}$. However, the model fails to reproduce the exact phase of the diurnal peak of long-duration and total PA over the areas west of $100^{\circ} \mathrm{E}$ (Fig. 9d, e).

\section{Possible causes related to the biases of the predicted precipitation}

\subsection{Moisture supply and low-level winds}

The possible mechanisms associated with the biases of atmospheric circulations leading to the errors in the 
(a)Obs Long / Total

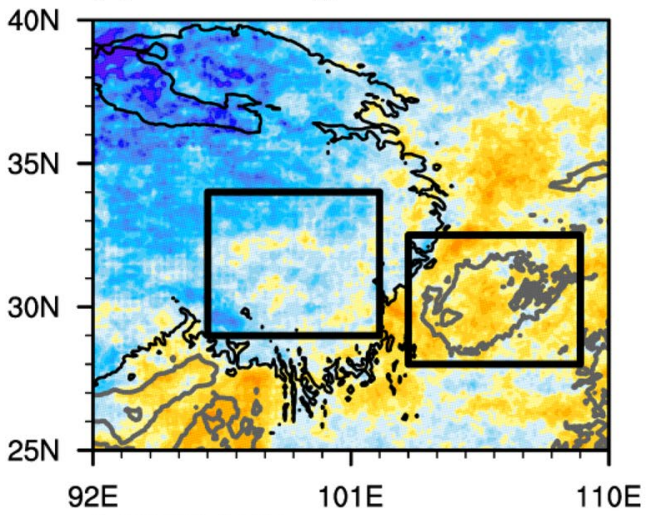

(c)WRF_NJU

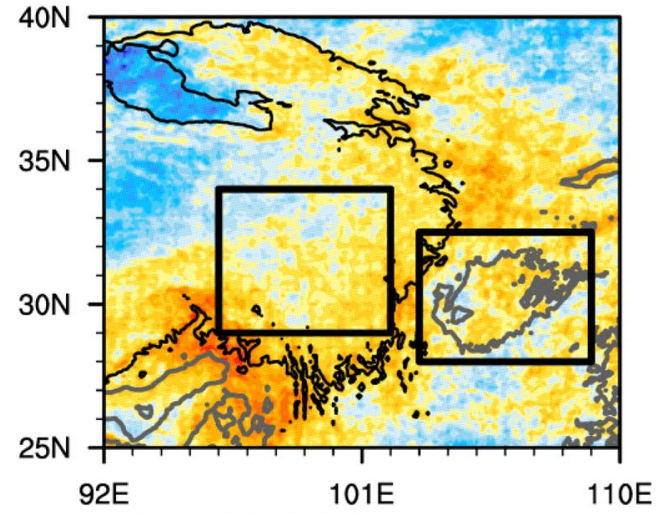

(e)Long WRF_NJU-Obs

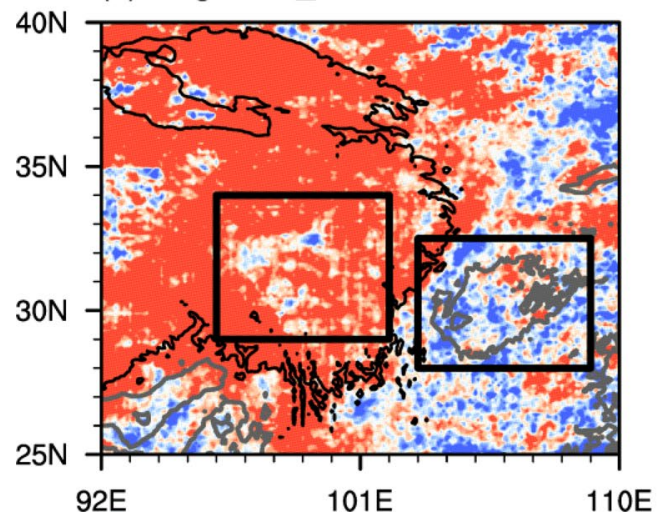

Fig. 7 Spatial distribution of the observed and predicted contributions of the long-duration PA and short-duration PA to the total PA averaged over 2013-2018 and the differences between WRF_NJU

\section{(b)Obs Short / Total}

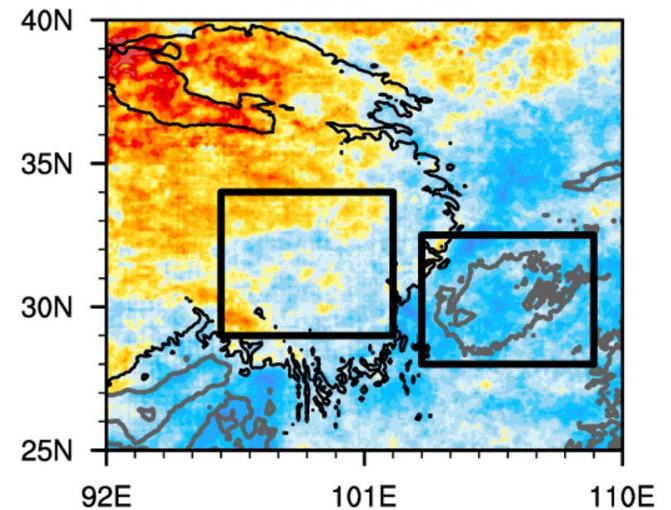

(d)WRF NJU

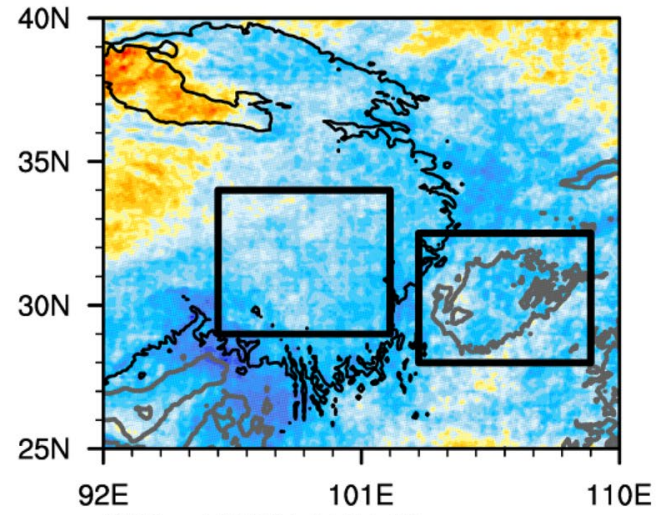

(f)Short WRF_NJU-Obs

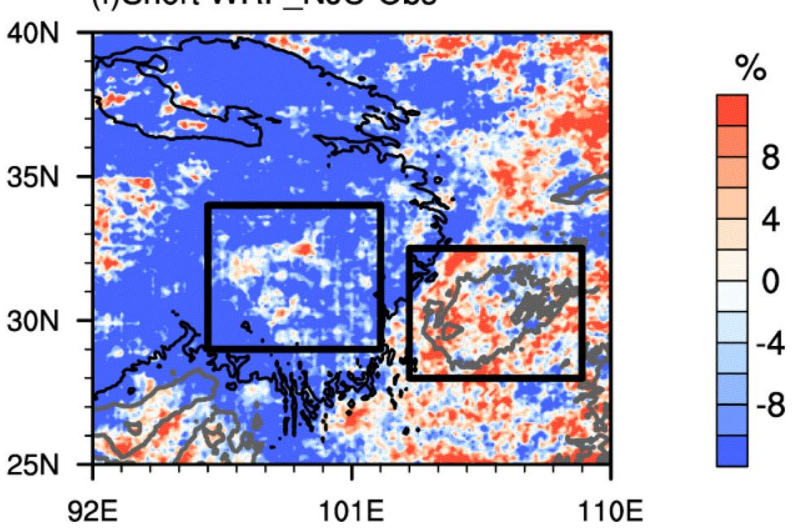

model prediction and observation in summer. The black (gray) lines denote the terrain height of 3000 (500) $\mathrm{m}$ and the black boxes denote the sub-region 1 (ETP) and sub-region 2 (Sichuan Basin) predicted rainfall over and around ETP will be discussed in the subsequent sections. Put simply, the precipitation is highly related to the net moisture flux and low-level circulation of the study regions. In this section, we mainly focus on the model performance in reproducing the summer mean and diurnal variation of the moisture condition and low-level winds over the study regions.

Figure 10 gives the summer mean atmospheric precipitable water vapor vertically integrated from the ground surface to $300 \mathrm{hPa}$ and the wind fields at $500 \mathrm{hPa}$ from the ERA5 reanalysis and the model prediction. Clearly, the atmospheric precipitable water vapor decreases from south to north over the whole domain with the magnitudes of $40 \mathrm{~mm}$ and $60 \mathrm{~mm}$ over the ETP and Sichuan Basin, respectively (Fig. 10a). The southwesterly winds at $500 \mathrm{hPa}$ encounters the south edge of the ETP bringing momentum and moist airflow to the ETP. We can observe the intense low-level westerly winds converge over the downstream areas of TP 
(a)Obs Long_Duration

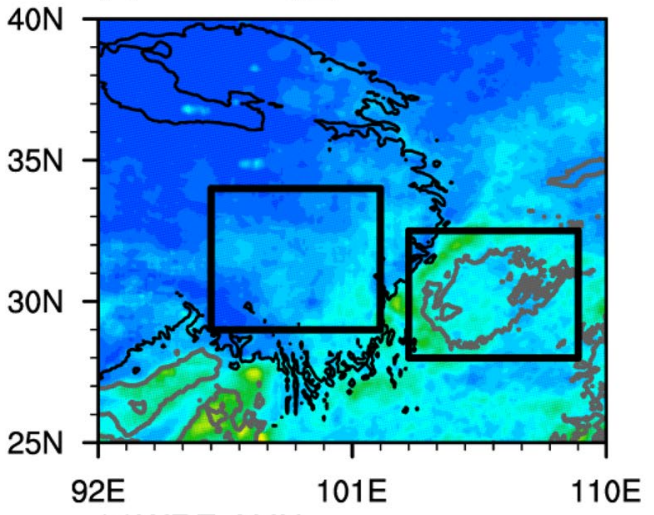

(c)WRF_NJU

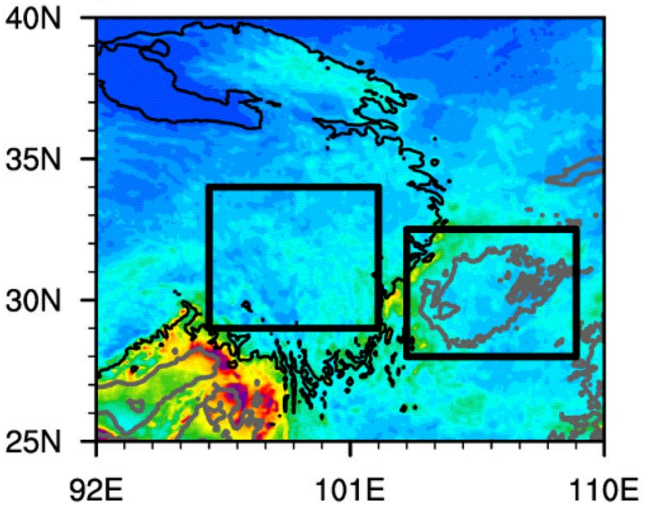

(e)Long WRF_NJU-Obs

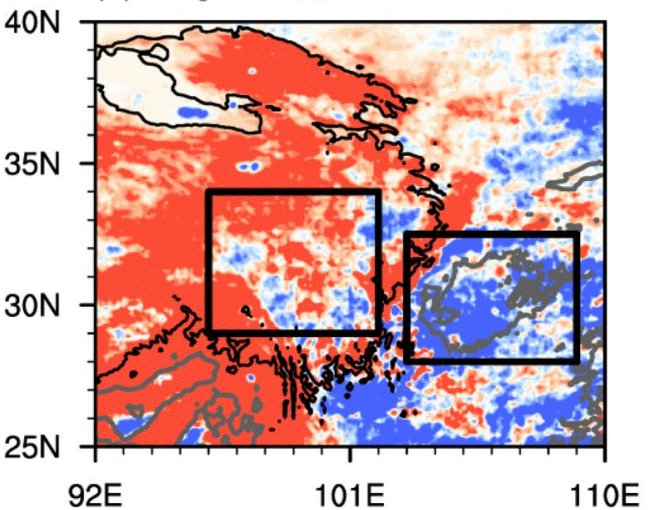

Fig. 8 Spatial distributions of the observed and predicted long-duration PA and short-duration PA averaged over 2013 2018 and the differences between WRF_NJU model prediction and observation

(Fig. 10a). The model well reproduces the spatial pattern of the vertically integrated precipitable water vapor and lowlevel winds (Fig. 10b), but the precipitable water vapor over the ETP is underestimated by about $6 \mathrm{~mm}$ and easterly wind biases can be noted over ETP (Fig. 10c). The underestimation of precipitable water vapor is possibly caused by the overestimated precipitation over the south slope of ETP with sharp terrain which consumes the water vapor transporting to the ETP (Fig. 2d, Fig. 8e, f). High resolution models can well resolve the complex terrains and consume the moisture
(b)Obs Short_Duration

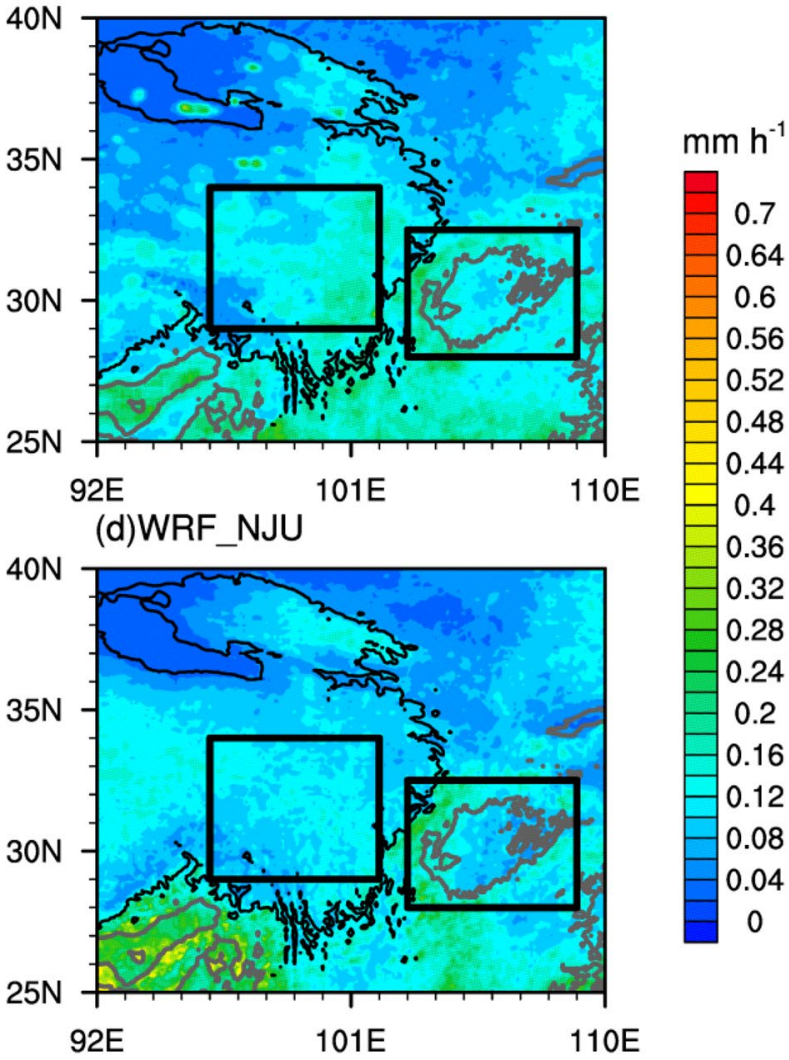

(f)Short WRF_NJU-Obs

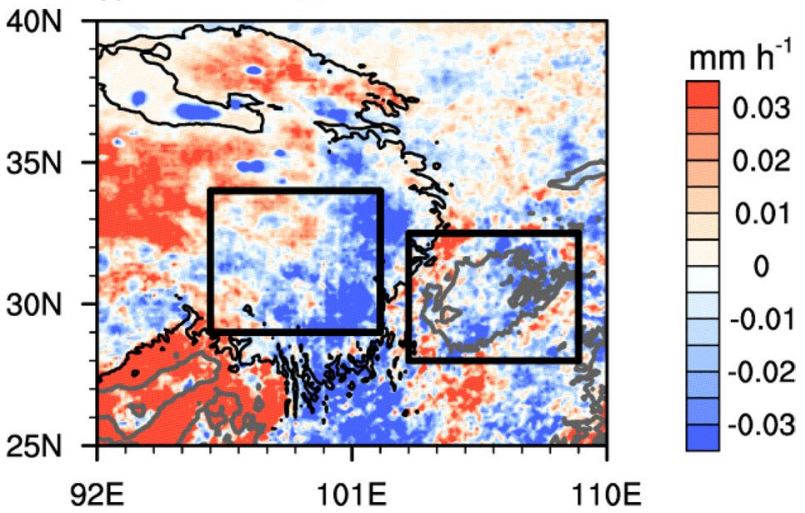

in summer. The black (gray) lines denote the terrain height of 3000 (500) $\mathrm{m}$ and the black boxes denote the sub-region 1 (ETP) and subregion 2 (Sichuan Basin)

over the south slope of Himalaya, thus the downstream moisture transport is weakened (Lin et al. 2018). In addition, the underestimation of the low-level westerly winds over ETP (sub-region 1) (Fig. 10c) can cause weakened water vapor transport, less precipitable water vapor and thereafter underestimated precipitation.

The summer mean low-level wind fields in nighttime and daytime are shown in Fig. 11. The mean westerly flow splits into two streams when passing TP, with one of the branches turning right and heading to the 


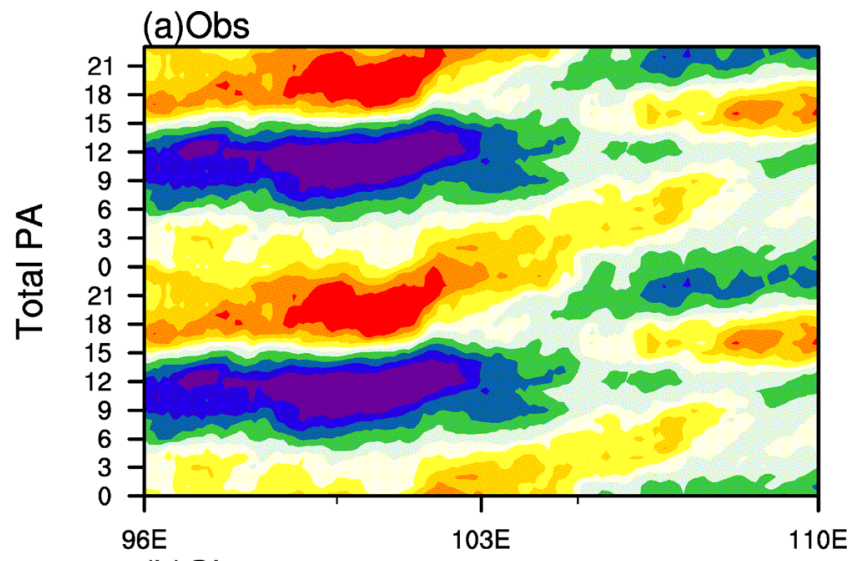

(b)Obs

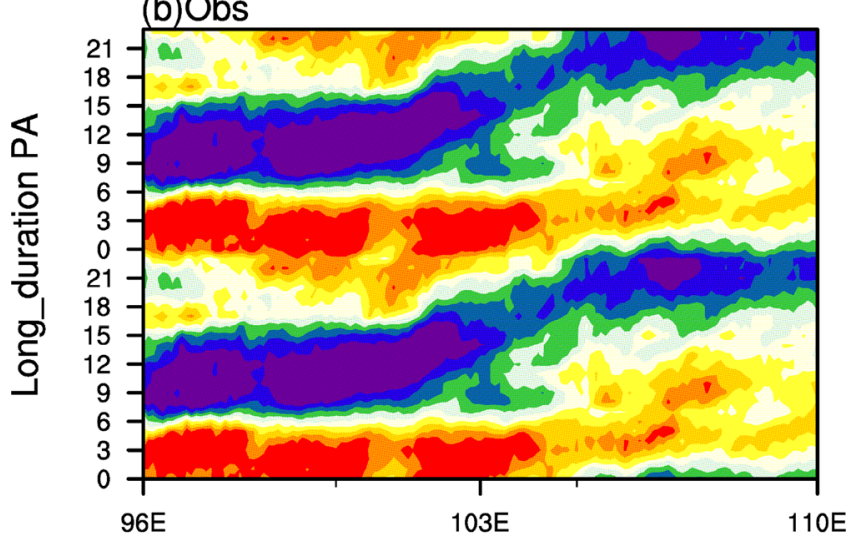

(c)Obs

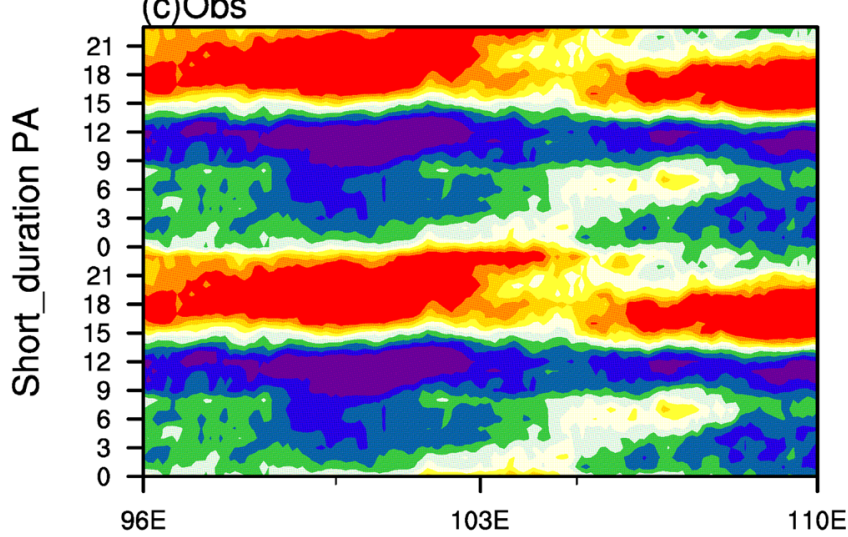

(d)WRF NJU
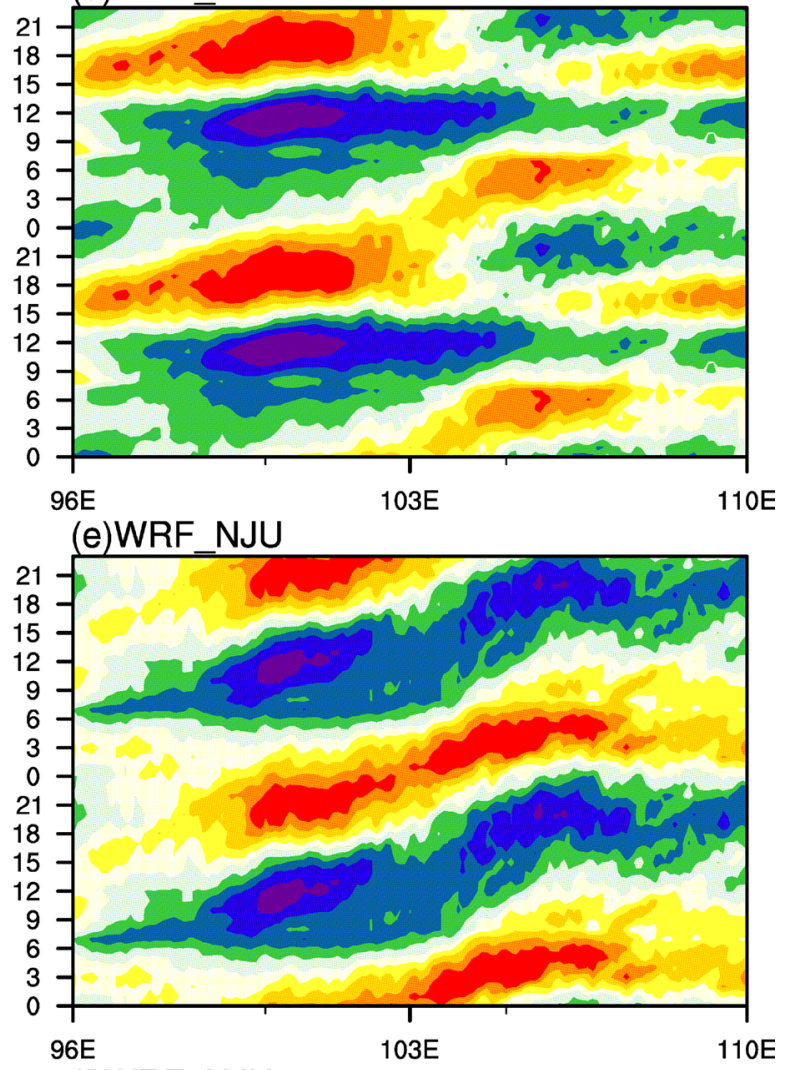

(f)WRF NJU

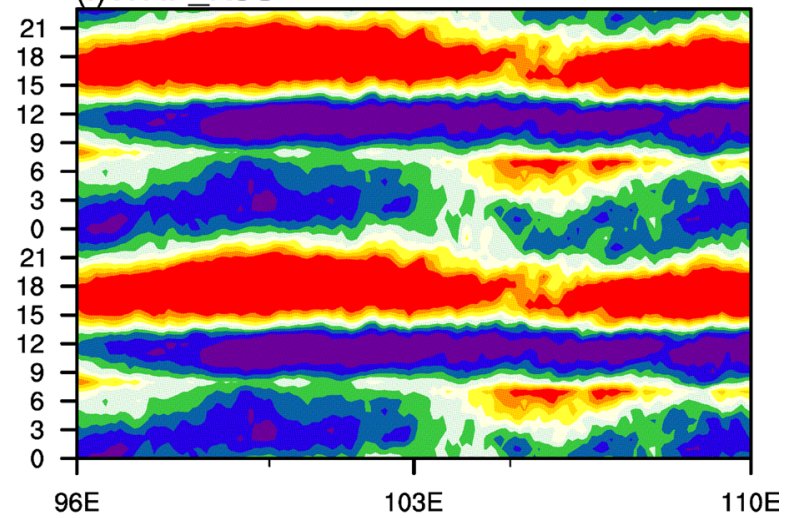

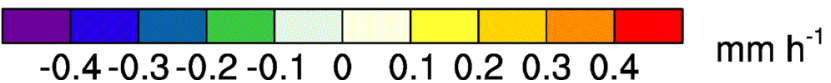

Fig. 9 Hovmöller diagrams of the normalized diurnal variation of the observed and predicted summer mean total, long-duration and short-duration PA during 2013 2018 averaged along $28^{\circ} \sim 40^{\circ} \mathrm{N}$

southeast part of the ETP where the PA is relatively large $\left(0.3 \sim 0.5 \mathrm{~mm} \mathrm{~h}^{-1}\right)$ during nighttime (Fig. 11a). Similarly, the southwesterly airflow also prevails over the ETP during daytime (Fig. 11b). Different from the situation during nighttime, the southwesterly low-level winds turn to east over the broad ETP (sub-region 1) during daytime. The PA over ETP is less during daytime than during nighttime (Fig. 11a, b). The model underestimates the low-level southwesterly and westerly winds with easterly wind biases over most ETP (sub-region 1) (Fig. 11e, f), and the underestimation is more evident during nighttime (Fig. 11e) compared to daytime (Fig. 11f). We further investigate the reason related to the easterly wind biases predicted by the model via analyzing the differences of air temperature at $500 \mathrm{hPa}$ between the model and ERA5, which shows warm biases over ETP and cold biases over 
Fig. 10 Spatial distribution of the summer mean vertically integrated (surface-300 hPa) atmospheric precipitable water vapor (shadings, units: $\mathrm{mm}$ ) tors, units: $\mathrm{m} \mathrm{s}^{-1}$ ) from ERA5 reanalysis and model prediction averaged over 2013-2018 and the differences between model prediction and ERF5. The black (gray) lines denote the terrain height of 3000 (500) $\mathrm{m}$ and the black boxes denote the subregion 1 (ETP) and sub-region 2 (Sichuan Basin) and wind fields at $500 \mathrm{hPa}$ (vec-
(a)ERA5

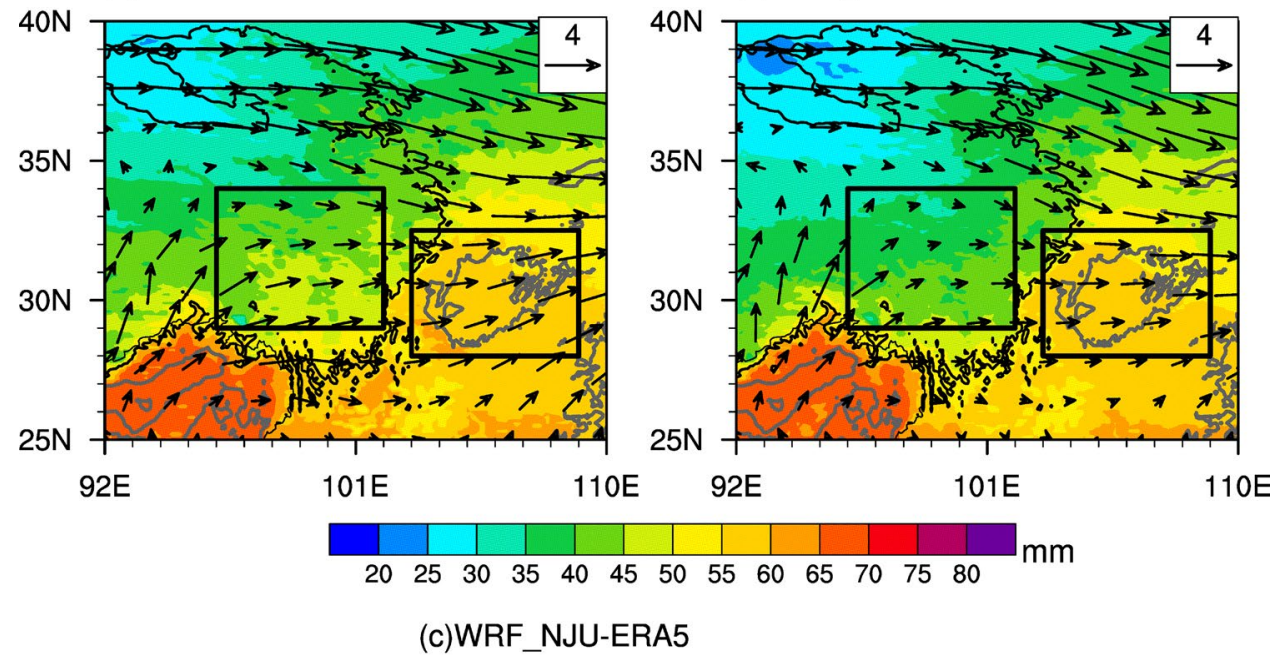

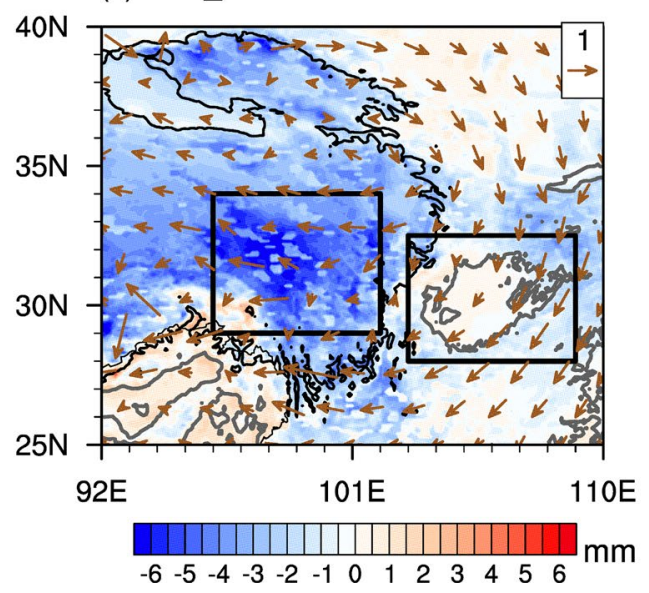

Sichuan Basin (not shown), leading to a west-east thermal contrast and thereafter easterly biases at $500 \mathrm{hPa}$ over ETP (sub-region 1) (Fig. 11e, f), where the PA and PF (Fig. 6a, b) are underestimated correspondingly.

Overall, the underestimated precipitable water vapor along with the much weaker southwesterly low-level winds (Fig. 10c) in the WRF_NJU model result in less water vapor transport over the ETP, which finally leads to the underestimated PA over the ETP (Figs. 2d, 6a). Over the Sichuan Basin, the model biases in the summer mean precipitable water vapor is not evident (Fig. 10c), while the southwesterly winds are much weaker in the model than in the observation (Figs. 10c, 11e, f).

\section{2 local thermal and dynamic conditions}

The local atmospheric thermal condition and the vertical motions are the key factors for the precipitation formation. In Sect. 3.3, we note that there are obvious biases of the short-/ long-duration precipitation forecast over ETP (sub-region1) and Sichuan Basin (sub-region 2). In this section, we will investigate the possible factors related to the biases of predicted short-/long-duration precipitation. The CAPE and MSE which can reflect the local atmospheric instability are indicated in the following sections.

Over ETP (sub-region 1), the WRF_NJU significantly underestimates the summer mean CAPE (Fig. 12c) compared to ERA5. The weaker CAPE predicted by WRF_NJU model is possibly related to the underestimated water vapor content over ETP. The short-duration rainfall events are highly related to convective precipitation (Yu et al. 2014). Low CAPE is clearly not favorable for the convective triggering. This well explains the underestimation of shortduration PA over most areas of the ETP (Fig. 8f). Figure 13 shows the vertical profiles of the anomalous (with the daily mean removed) MSE, dry static energy, latent static energy at 20:00 BJT and 08:00 BJT regionally averaged over ETP (sub-region 1) during 2013-2018. From ERA5, the anomalous MSE is small at 08:00 BJT (Fig. 13a), indicating the stable atmospheric condition. Meanwhile, much 
Fig. 11 The summer PA (shadings, units: $\mathrm{mm} \mathrm{h}^{-1}$ ) and wind fields at $500 \mathrm{hPa}$ (vectors, units: $\mathrm{m} \mathrm{s}^{-1}$ ) averaged during 18:00 06:00 BJT (nighttime) and 06:00 18:00 BJT (daytime) from the ERA5 reanalysis, gauge-satellite merged precipitation dataset and the WRF_NJU prediction during 2013-2018 and the differences between prediction and observation. The black (gray) lines denote the terrain height of 3000 (500) $\mathrm{m}$ and the black boxes denote the sub-region 1 (ETP) and sub-region 2 (Sichuan Basin)
(a)ERA5 18:00--06:00 BJT
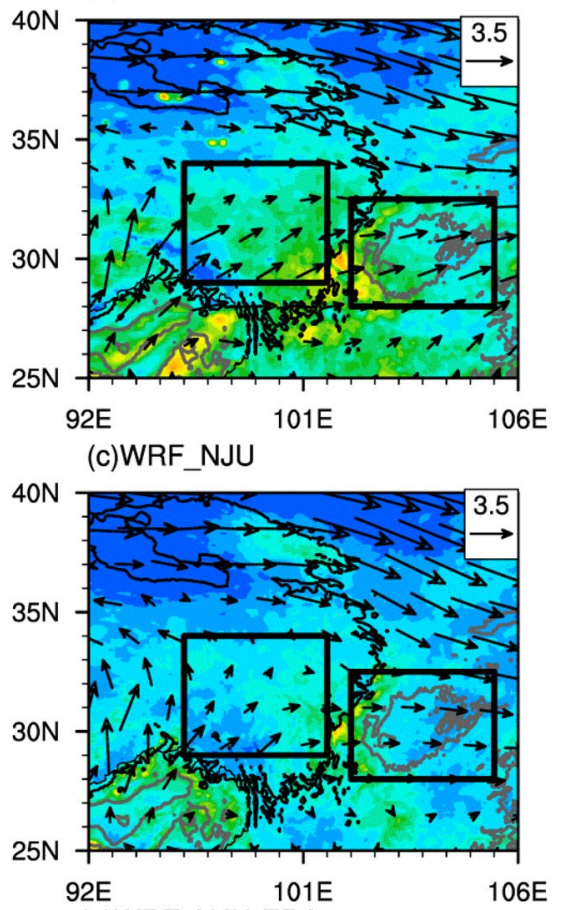

(e)WRF_NJU-ERA5

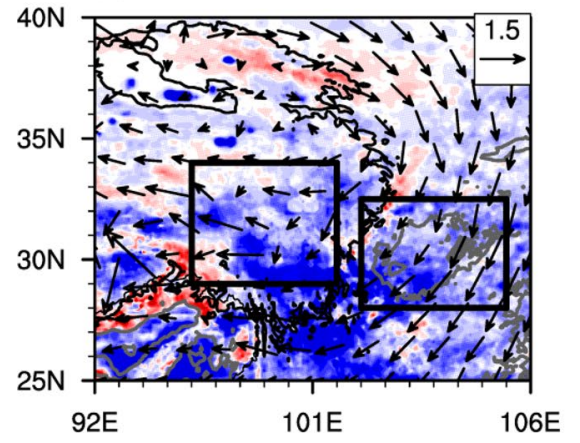

(b)ERA5 06:00--18:00 BJT
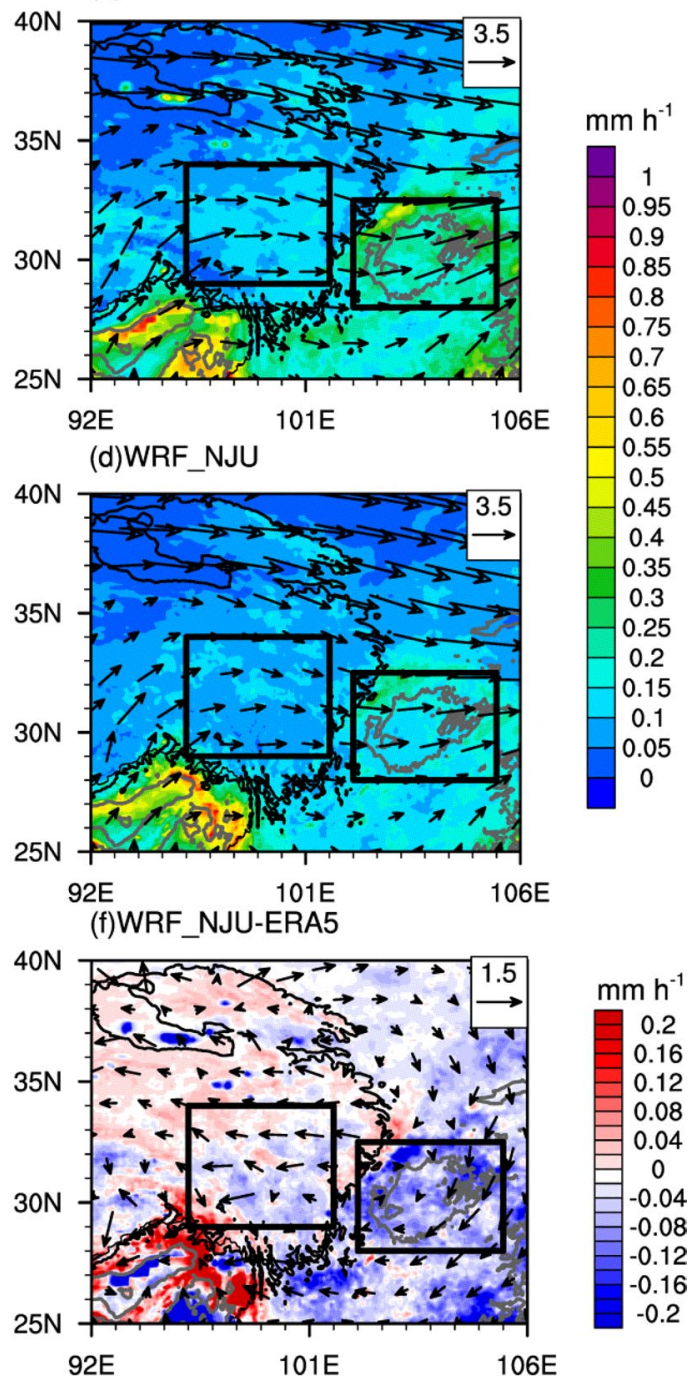

stronger MSE at 20:00 BJT which enhances quickly below $400 \mathrm{hPa}$ and reaches the maximum at $500 \mathrm{hPa}$ (Fig. 13a), the increased MSE gradients in the low level at 20:00 BJT provides favorable conditions for the upward movement and thereafter the precipitation formation over ETP. The largest dry static energy emerges at the near surface layer (around $500 \mathrm{hPa}$ ) (Fig. 13a), which is related to the heating from the land surface. The latent static energy decreases with the altitude at 20:00 BJT (Fig. 13a), indicating the strong vertical transport of the specific humidity occurs at the near surface. Overall, the WRF_NJU model well depicts the trends of the MSE and its components (Fig. 13b). Compared to the ERA5 reanalysis, the MSE is much weaker at the near surface level, suggesting less intense upward motions in the model, which is consistent with the more stable atmospheric condition. Both results of the CAPE and the MSE (Figs.12, 13) indicate less active convection and weaker upward movement in the model than in ERA5. Those factors may finally lead to the underestimated precipitation over ETP.

Similar to the situation over ETP, the model also underestimates the summer mean CAPE over Sichuan Basin (Fig. 12c). However, the bias in the precipitable water vapor over Sichuan Basin is not evident (Fig. 10c) and is not the main factor for the predicted precipitation biases. Figure 14 further presents the $2 \mathrm{~m}$ surface temperature over the Sichuan Basin from WRF_NJU and ERA5 and their differences. It can be seen that WRF_NJU model significantly underestimates the surface air temperature (Fig. 14c), indicating that the heating effect from the land surface is underestimated by WRF_NJU. Recent study (Zhang et al. 2019) found that the inertial oscillations of boundary layer play a key role in modulating the diurnal cycles of precipitation in Sichuan Basin. The underestimated near surface air temperature makes the boundary layer more stable, resulting in relatively lower CAPE (Fig. 12c). This finally leads to much 
Fig. 12 The summer mean convective available potential energy (shading, units: $\mathrm{J} \mathrm{kg}^{-1}$ ) from the ERA5 reanalysis model prediction averaged over 2013-2018 and the differences between model prediction and ERA5. The black (gray) lines denote the terrain height of 3000 (500) $\mathrm{m}$ and the black boxes denote the sub-region 1 (ETP) and sub-region 2 (Sichuan Basin). The dots indicate the differences over 95\% significant confidence level of $t$ test

\section{(a)ERA5}

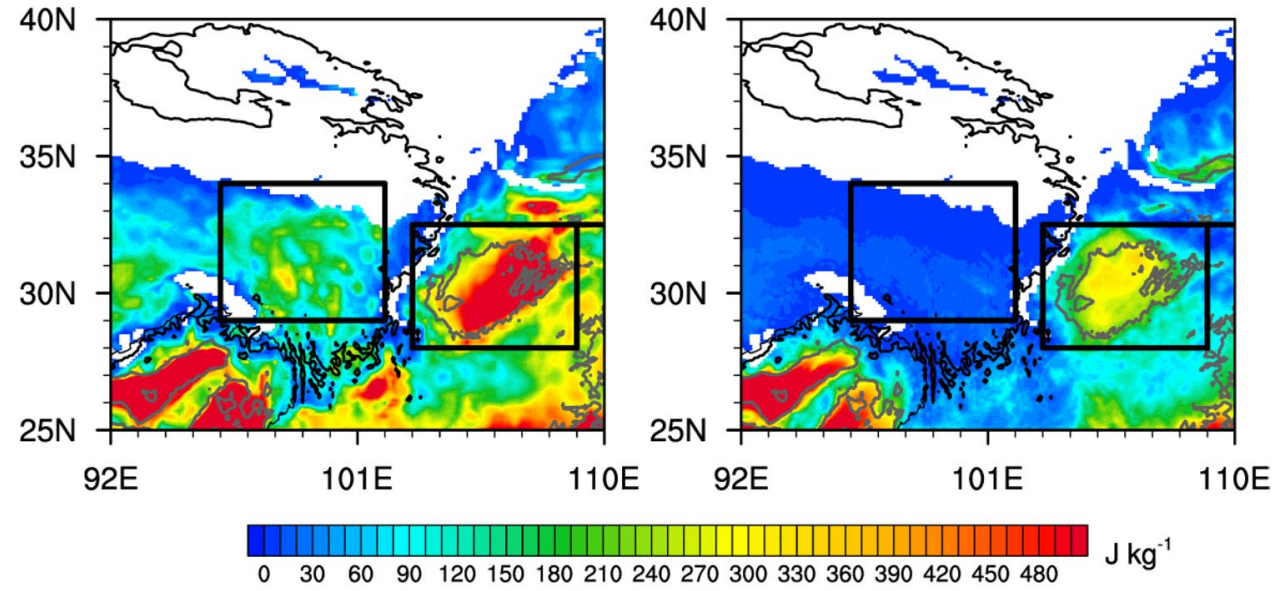

(c)WRF_NJU-ERA5

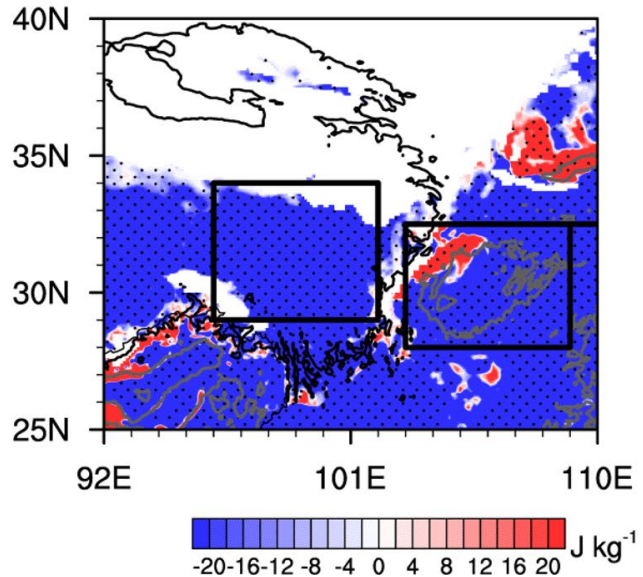

(a)ERA5 ETP

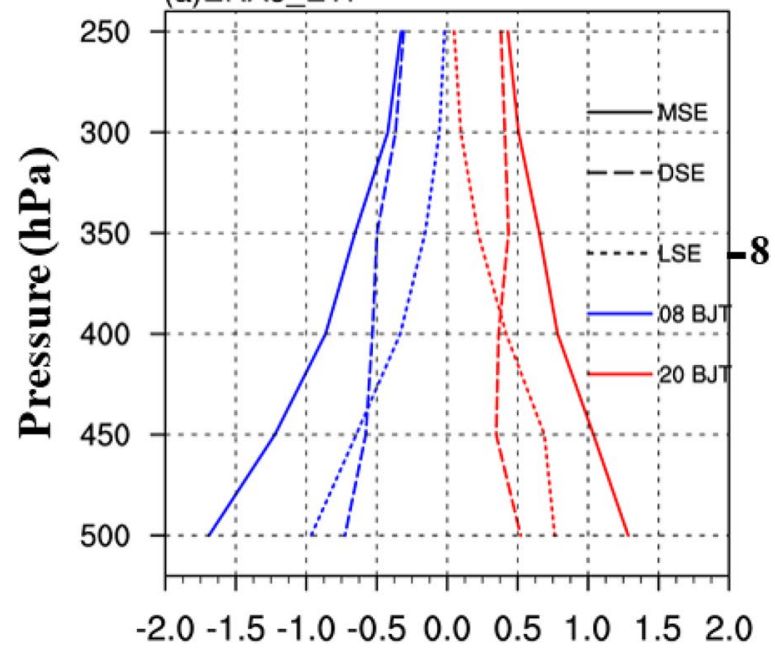

(b)WRF NJU ETP

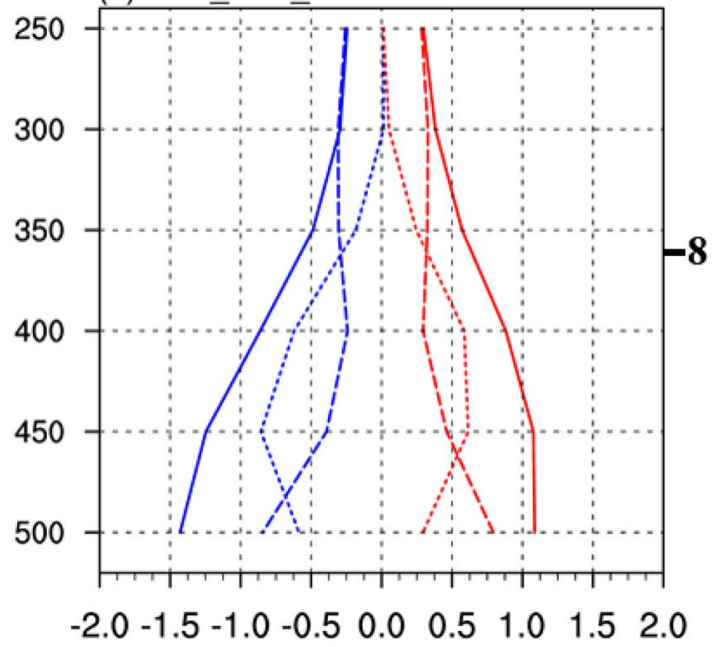

Fig. 13 Profiles of the anomalous (with the daily mean removed) moist static energy (MSE, solid lines), dry static energy (DSE, dashed lines) and latent static energy (LSE, dot lines; units: $10^{3} \mathrm{~m}^{2} \mathrm{~s}^{-2}$ ) from the ERA5 reanalysis and model prediction at 08:00 BJT (blue) and 20:00 BJT (red) during 2013 2018 regionally averaged over the ETP 
Fig. 14 The ERA5 and WRF_ NJU predicted summer mean $2 \mathrm{~m}$ temperature averaged over 2013-2018 over the Sichuan Basin and the differences between model prediction and ERA5. The black lines denote the terrain height of $500 \mathrm{~m}$. The dots indicate the differences over $95 \%$ significant confidence level of $t$ test
(a)ERA5 Reg2

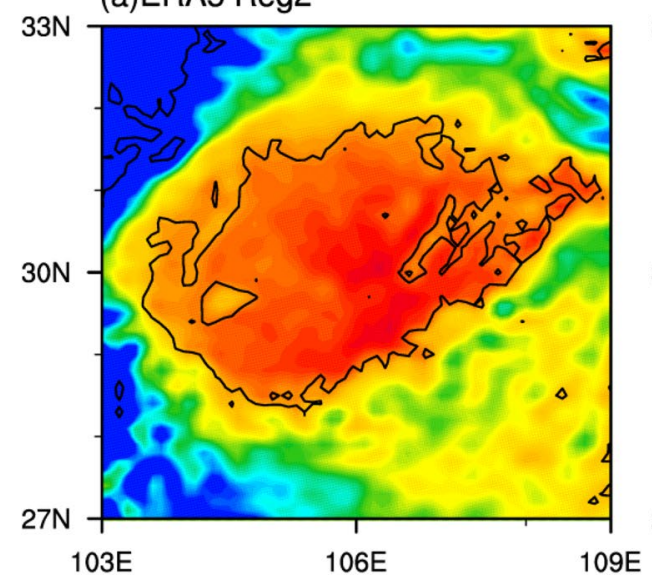

(b)WRF_NJU Reg2

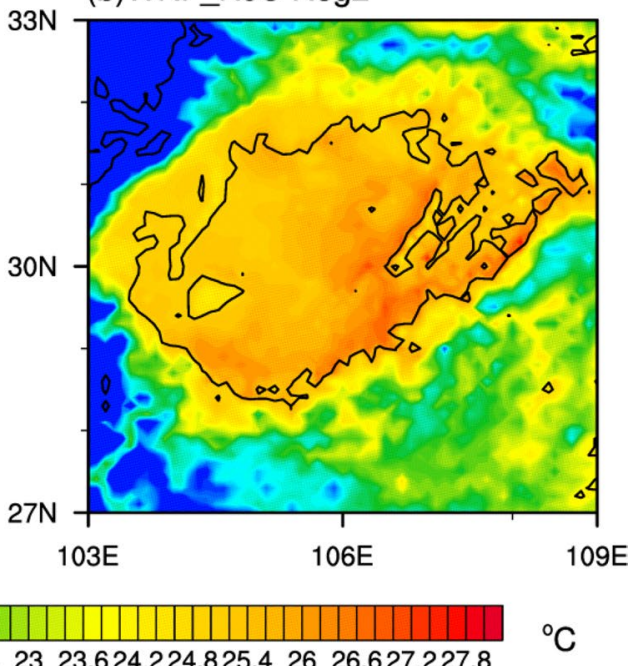

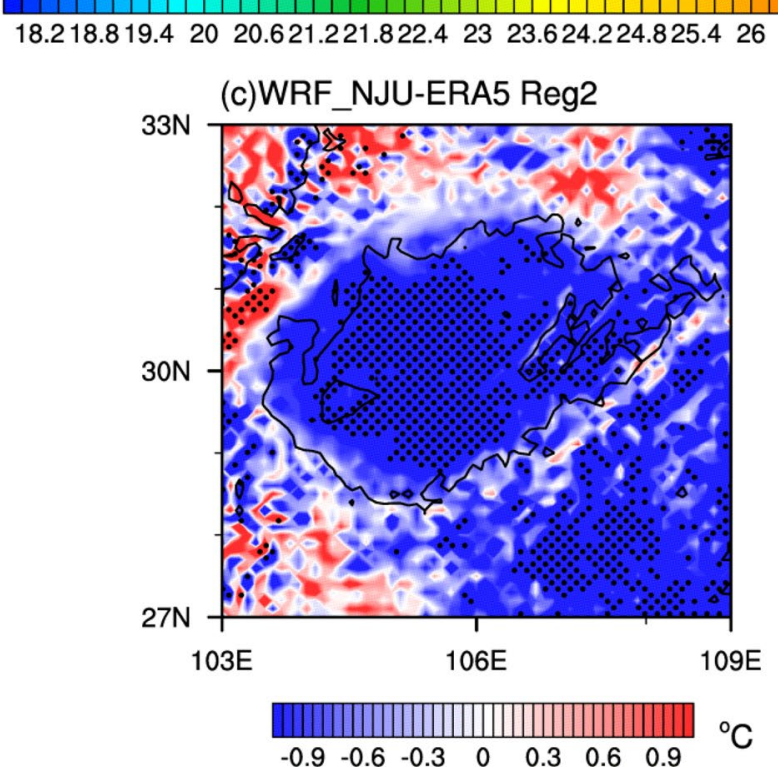

weaker vertical motion over Sichuan Basin. As shown in Fig. 15a, b, the upward motion prevails over Sichuan Basin at most time of a day except for the short period between 12:00 (noon) and 20:00 BJT (late afternoon). It can also be noted that the vertical velocity predicted by WRF_NJU model is relatively weaker than the ERA5 at most time of a day (Fig. 15c). The relatively weaker vertical motion in WRF_NJU model is not favorable for the precipitation formation and leads to underestimated PA with both long- and short-duration over Sichuan Basin (Fig. 8e, f).

Overall, the underestimation of short-duration PA over ETP (sub-region 1) is closely related to the underestimated MSE and CAPE in the WRF_NJU model. However, the underestimated PA over Sichuan Basin (sub-region 2) is mainly related to the underestimated near surface air temperature which leads to relatively weaker updraft compared to the ERA5 reanalysis.

\section{Summary and discussion}

We utilize the hourly gauge-satellite merged precipitation product with the spatial resolution of $0.1^{\circ} \times 0.1^{\circ}$ to evaluate how well the convection-permitting WRF_NJU model predicts the precipitation diurnal cycles and its propagating features over the ETP and its surrounding regions in summer. Possible causes related to the modeled precipitation biases are also revealed and discussed.

The main findings are summarized as follows:

(1) The convection-permitting WRF_NJU model can well reproduce the spatial distribution of the observed PA, PF and PI over and around the ETP with complex terrain in summer. However, the model tends to underestimate the PA and PF mainly due to the underestimation of precipitation of $1 \sim 4 \mathrm{~mm} \mathrm{~h}^{-1}$. The spatial distribution of the precipitation diurnal peak times over most 
Fig. 15 Diurnal variation of mean vertical velocity during 00:00 23:00 BJT over 2013-2018 regionally averaged over Sichuan Basin from the ERA5 reanalysis and model prediction at different levels and the difference between model and ERA5

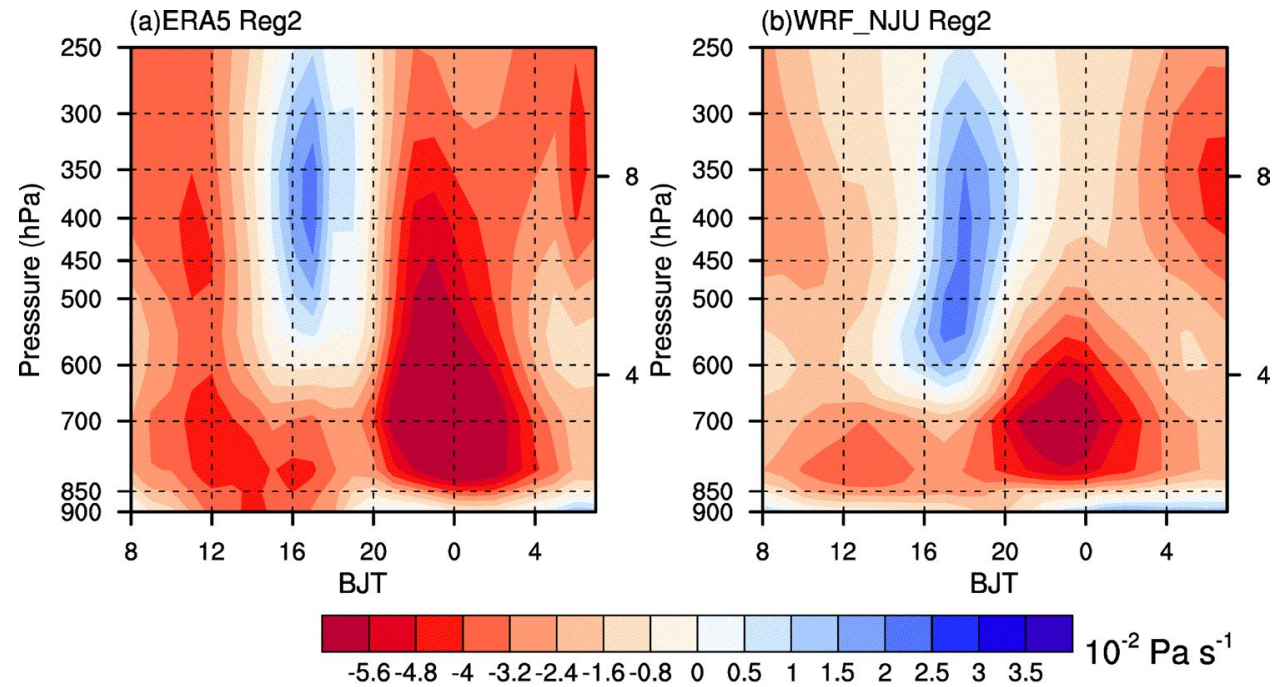

(c)WRF_NJU-ERA5 Reg2

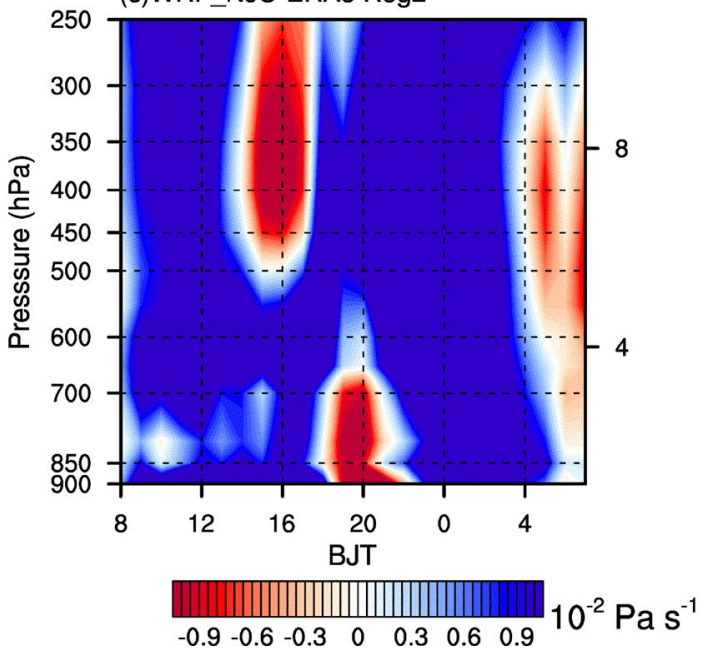

the total, long-duration and short-duration precipitation can be realistically captured by the WRF_NJU model.

(3) Further analysis of the possible causes related to the modeled precipitation biases suggests that the underestimated rainfall is mainly attributed to the underestimated atmospheric precipitable water vapor and low-level southwesterly winds over the ETP. The WRF_NJU model produces too much rainfall in south TP which over consumes the water vapor in the upstream. The general environmental bias of moisture leads to relatively weaker CAPE which finally results in less short-duration precipitation over ETP.

(4) Compared to ERA5, the cold bias of near surface air temperature leads to much more stable atmosphere at low level, resulting in less CAPE and weaker vertical motion and thereafter underestimated PA over Sichuan Basin. 
This study principally evaluates the ability of the WRF NJU model real-time forecast with convection-permitting resolution over and around the ETP. From the overall analysis, the model still has apparent biases in producing the magnitudes and diurnal phases of precipitation over the ETP. Yu et al. (2014) indicated that, besides increasing the horizontal resolution, improvements in precipitation related physical parameterizations are also important for better portraying the diurnal evolution of rainfall. The surface heterogeneities of TP influences the diurnal variations of surface radiation fluxes (Müller et al. 2005) and affects the precipitation diurnal variation through atmospheric circulation. To more accurately depict the land surface inhomogeneity, many sub-grid terrain radiative forcing schemes have been set up and employed in numerical models. Lee et al. (2012) employed the "3-D Monte Carlo" parameterization scheme and found that the 3-D mountain radiation effects result in larger sensible and latent heat transfer between the surface and the atmosphere over the TP. Zhang et al. (2006) and Gu et al. (2020) employed the sub-grid terrain radiative forcing schemes in the climate models that well represent the spatial distribution of temperature over the eastern part of the TP compared to the observation and alleviate the modeled precipitation biases over China during summer. The altitude, terrain slope, orientation, sky-view factors and other terrain parameters all have effects on the surface radiation fluxes. In our present model, we have not considered these parameters in surface radiation schemes and this may lead to the underestimation of the thermal contrasts between the distinct underlying surface. The improper prediction of the thermal forcing may generate the model errors. Therefore, we intend to couple the sub-grid terrain radiative forcing scheme in the WRF_NJU model to further improve the performance of the model in predicting precipitation over and around the ETP in the further work.

Acknowledgements This study is supported by the National Key Research and Development Program of China (Grant No. 2018YFC1507604), National Natural Science Foundation of China (Grants 41975081 and 41975130 ), the bilateral research project GZ1259 of the Sino-German Center for Research Support, CAS "Light of West China" Program, and the Jiangsu University "Blue Project" outstanding young teachers training object, and the Fundamental Research Funds for the Central Universities and the Jiangsu Collaborative Innovation Center for Climate Change.

Open Access This article is licensed under a Creative Commons Attribution 4.0 International License, which permits use, sharing, adaptation, distribution and reproduction in any medium or format, as long as you give appropriate credit to the original author(s) and the source, provide a link to the Creative Commons licence, and indicate if changes were made. The images or other third party material in this article are included in the article's Creative Commons licence, unless indicated otherwise in a credit line to the material. If material is not included in the article's Creative Commons licence and your intended use is not permitted by statutory regulation or exceeds the permitted use, you will need to obtain permission directly from the copyright holder. To view a copy of this licence, visit http://creativecommons.org/licenses/by/4.0/.

\section{References}

Bao X, Zhang F, Su J (2011) Diurnal variations of warm-season precipitation east of the Tibetan Plateau over China. Mon Weather Rev 139:2790-2810. https://doi.org/10.1175/ MWR-D-11-00006.1

Bao X, Zhang F (2013) Evaluation of NCEP-CFSR, NCEP-NCAR, ERA-Interim, and ERA-40 reanalysis datasets against independent sounding observations over the tibetan plateau. J Clim 26:206-214

Ban N, Schmidli J, Schär C (2014) Evaluation of the convectionresolving regional climate modeling approach in decade-long simulations. J Geophys Res Atmos 119:7889-7907. https://doi. org/10.1002/2014jd021478

Belmonte Rivas M, Stoffelen A (2019) Characterizing ERA-Interim and ERA5 surface wind biases using ASCAT. Ocean Sci $15: 831-852$

Bonavita M, Hólm EV, Isaksen L, Fisher M (2016) The evolution of the ECMWF hybrid data assimilation system. Q J R Meteorol Soc 142:287-303

Browning KA et al (2007) The convective storm initiation project. B Am Meteorol Soc 88:1939-1955

Carbone RE, Tuttle JD, Ahijevych DA, Trier SB (2002) Inferences of predictability associated with warm season precipitation episodes. J Atmos Sci 59:2033-2056. https://doi.org/10.1175/ 1520-0469(2002)059\%3c2033:IOPAWW\%3e2.0.CO;2

Chakraborty A, Krishnamurti TN (2008) Improved forecasts of the diurnal cycle in the tropics using multiple global models. Part II: Asian Summer Monsoon. J Clim 21:4045-4067. https://doi. org/10.1175/2008JCLI2107.1

Chan SC, Kendon EJ, Fowler HJ, Blenkinsop S, Roberts NM, Ferro CAT (2014) The value of high-resolution met office regional climate models in the simulation of multihourly precipitation extremes. J Clim 27:6155-6174. https://doi.org/10.1175/ JCLI-D-13-00723.1

Chang W, Wang J, Marohnic J, Kotamarthi VR, Moyer EJ (2018) Diagnosing added value of convection-permitting regional models using precipitation event identification and tracking. Clim Dyn. https://doi.org/10.1007/s00382-018-4294-0

Chen G, Sha W, Iwasaki T (2009) Diurnal variation of precipitation over southeastern China: 2 Impact of the diurnal monsoon variability. J. Geophys. Res. Atmos. 114:D21105. https://doi.org/ 10.1029/2009JD012181

Chen G, Sha W, Sawada M, Iwasaki T (2013) Influence of summer monsoon diurnal cycle on moisture transport and precipitation over eastern China. J Geophys Res Atmos 118:3163-3177. https://doi.org/10.1002/jgrd.50337

Chen G, Lan R, Zeng W, Pan H, Li W (2018) Diurnal variations of rainfall in surface and satellite observations at the monsoon coast (South China). J Clim 31:1703-1724. https://doi.org/10. 1175/JCLI-D-17-0373.1

Chen H, Yu R, Li J, Yuan W, Zhou T (2010) Why nocturnal longduration rainfall presents an eastward-delayed diurnal phase of rainfall down the Yangtze River valley. J Clim 23:905-917. https://doi.org/10.1175/2009JCLI3187.1

Clark AJ, Gallus WA, Chen T (2007) Comparison of the diurnal precipitation cycle in convection-resolving and non-convection-resolving mesoscale models. Mon Weather Rev 135:34563473. https://doi.org/10.1175/MWR3467.1 
Collins W, Rasch PJ, Boville BA, McCaa J, Williamson DL, Kiehl JT et al (2004) Description of the NCAR community atmosphere model (CAM 3.0) (No. NCAR/TN-464+STR). Univ Corp Atmos Res. https://doi.org/10.5065/D63N21CH

Dai A, Giorgi F, Trenberth KE (1999) Observed and model-simulated diurnal cycles of precipitation over the contiguous United States. J Geophys Res Atmos 104:6377-6402. https://doi.org/ 10.1029/98JD02720

Dai A, Trenberth KE (2004) The diurnal cycle and its depiction in the community climate system model. J Clim 17:930951. https://doi.org/10.1175/1520-0442(2004)017\%3c0930: TDCAID \%3e2.0.CO;2

Dee DP et al (2011) The ERA-Interim reanalysis: configuration and performance of the data assimilation system. Q J R Meteorol Soc 137:553-597

Fowle MA, Roebber PJ (2003) Short-range (0-48 h) numerical prediction of convective occurrence, mode, and location. Weather Forecast 18:782-794. https://doi.org/10.1175/15200434(2003)018\%3c0782:SHNPOC\%3e2.0.CO;2

Fujinami H, Nomura S, Yasunari T (2005) Characteristics of diurnal variations in convection and precipitation over the southern Tibetan Plateau during summer. SOLA 1:49-52. https://doi. org/10.2151/sola.2005-014

Gao Y, Cuo L, Zhang Y (2014) Changes in moisture flux over the Tibetan Plateau during 1979-2011 and possible mechanisms. J Clim 27:1876-1893. https://doi.org/10.1175/jcli-d-13-00321.1

Geng B, Yamada H (2007) Diurnal variations of the Meiyu/Baiu rain belt. SOLA 3:61-64. https://doi.org/10.2151/sola.2007-016

Gu C, Huang A, Wu Y, Yang B, Mu X, Zhang X, Cai S (2020) Effects of subgrid terrain radiative forcing on the ability of RegCM4.1 in the simulation of summer precipitation over China. J Geophys Res Atmos 125:e2019JD032215. https:// doi.org/10.1029/2019JD032215

Guo Z, Fang J, Sun X, Tang J, Yang Y, Tang J (2019) Decadal long convection-permitting regional climate simulations over eastern China: evaluation of diurnal cycle of precipitation. Clim Dyn 54:1329-1349. https://doi.org/10.1007/ s00382-019-05061-z

He H, Zhang F (2010) Diurnal variations of warm-season precipitation over Northern China. Mon Weather Rev 138:1017-1025. https:// doi.org/10.1175/2010MWR3356.1

Heath NK (2014) Using a WRF simulation to examine regions where convection impacts the Asian summer monsoon anticyclone

Hersbach $\mathrm{H}$ et al (2020) The ERA5 global reanalysis. Q J R Meteorol Soc. https://doi.org/https://doi.org/10.21957/tkic6g3wm

Higgins RW, Yao Y, Yarosh ES, Janowiak JE, Mo KC (1997) Influence of the great plains low-level jet on summertime precipitation and moisture transport over the central United States. J Clim 10:481-507. https://doi.org/10.1175/1520-0442(1997)010\% 3c0481:IOTGPL\%3e2.0.CO;2

Hu Q, Jiang D, Fan G (2014) Evaluation of CMIP5 models over the Qinghai-Tibetan Plateau (Chinese with English abstract). Chin J Atmos Sci 38:924-938

Huang A, Zhao Y, Zhou Y, Yang B, Zhang L, Dong X, Fang D, Wu Y (2016) Evaluation of multisatellite precipitation products by use of ground-based data over China. J Geophys Res Atmos 121:10-654. https://doi.org/10.1002/2016JD025456

Huang H, Wang C, Chen GT, Carbone RE (2010) The role of diurnal solenoidal circulation on propagating rainfall episodes near the Eastern Tibetan Plateau. Mon Weather Rev 138:2975-2989. https://doi.org/10.1175/2010MWR3225.1

Ji X, Wu H, Huang A, Zhao W, Wu Y (2017) Characteristics of the precipitation diurnal cariation over Qinghai-Tibetan plateau in summer. Plateau Meteorol 36:1188-1200
Jiang D, Tian Z, Lang X (2015) Reliability of climate models for China through the IPCC Third to Fifth Assessment Reports. Int J Climatol 36:1114-1133. https://doi.org/10.1002/joc.4406

Jiang Z, Zhang D, Xia R, Qian T (2017) Diurnal variations of presummer rainfall over Southern China. J Clim 30:755-773. https://doi. org/10.1175/JCLI-D-15-0666.1

Jin X, Wu T, Li L (2013) The quasi-stationary feature of nocturnal precipitation in the Sichuan Basin and the role of the Tibetan Plateau. Clim Dyn 41:977-994. https://doi.org/10.1007/ s00382-012-1521-y

Joyce RJ, Janowiak JE, Arkin PA, Xie P (2004) CMORPH: a method that produces global precipitation estimates from passive microwave and infrared data at high spatial and temporal resolution. J Hydrometeorol 5:487-503. https://doi.org/10.1175/15257541(2004)005\%3c0487:CAMTPG\%3e2.0.CO;2

Kalverla PC, Duncan JB Jr, Steeneveld G-J, Holtslag AAM (2019) Low-level jets over the North Sea based on ERA5 and observations: together they do better. Wind Energy Sci 4:193-209

Kang S, Im E-S, Ahn J-B (2014) The impact of two land-surface schemes on the characteristics of summer precipitation over East Asia from the RegCM4 simulations. Int J Climatol 34:39863997. https://doi.org/10.1002/joc.3998

Kishtawal CM, Krishnamurti TN (2001) Diurnal variation of summer rainfall over taiwan and its detection using TRMM observations. J Appl Meteorol 40:331-344. https://doi.org/10.1175/ 1520-0450(2001)040\%3c0331:DVOSRO\%3e2.0.CO;2

Kouadio K, Bastin S, Konare A, Ajayi VO (2018) Does convectionpermitting simulate better rainfall distribution and extreme over Guinean coast and surroundings? Clim Dyn. https://doi.org/10. 1007/s00382-018-4308-y

Kramer M, Heinzeller D, Hartmann H, van den Berg W, Steeneveld G-J (2018) Assessment of MPAS variable resolution simulations in the grey-zone of convection against WRF model results and observations. Clim Dyn. https://doi.org/10.1007/ s00382-018-4562-z

Lee WL, Liou KN, Wang C (2012) Impact of 3-D topography on surface radiation budget over the Tibetan Plateau. Theor Appl Climatol 113:95-103. https://doi.org/10.1007/s00704-012-0767-y

Li J, Yu R, Zhou T (2008) Seasonal variation of the diurnal cycle of rainfall in southern contiguous China. J Clim 21:6036-6043. https://doi.org/10.1175/2008JCLI2188.1

Li P, Furtado K, Zhou T, Chen H, Li J, Guo Z, Xiao C (2018) The diurnal cycle of East Asian summer monsoon precipitation simulated by the Met Office Unified Model at convection-permitting scales. Clim Dyn. https://doi.org/10.1007/s00382-018-4368-z

Li P, Furtado K, Zhou T, Chen H, Li J (2020a) Convection-permitting modelling improves simulated precipitation over the central and eastern Tibetan Plateau. Q J R Meteorol Soc 147:341-362

Li NN, Li J, Rong XY et al (2020b) Obtaining more information about precipitation biases over East Asia from hourly scale evaluation of model simulation. J Meteorol Res 34:515-528. https://doi.org/ 10.1007/s13351-020-9147-1

Liang XZ, Li L, Dai A, Kunkel KE (2004) Regional climate model simulation of summer precipitation diurnal cycle over the United States. Geophys Res Lett. https://doi.org/10.1029/2004GL0210 54

Lin J, Yang GM (2014) Spatial-temporal characteristics of rainstorm in China during 1981-2010. Meteorol Mon 40:816-826

Lin C, Chen D, Yang K, Ou T (2018) Impact of model resolution on simulating the water vapor transport through the central Himalayas: implication for models' wet bias over the Tibetan Plateau. Clim Dyn 51:3195-3207. https://doi.org/10.1007/ s00382-018-4074-x

Liu C, Ikeda K, Rasmussen R, Barlage M, Newman AJ, Prein AF, Yates D et al (2016) Continental-scale convection-permitting 
modeling of the current and future climate of North America. Clim Dyn 49:71-95. https://doi.org/10.1007/s00382-016-3327-9

Lu P, Yu R, Zhou T (2003) Numerical simulation of the mid-night rainfall over Sichuan Basin during August 2003. Acta Meteorol Sin 66:371-380

Maycock AC, Randel WJ, Steiner AK, Karpechko AY, Christy J et al (2018) Revisiting the mystery of recent stratospheric temperature trends. Geophys Res Lett 45:9919-9933. https://doi.org/10.1029/ 2018GL078035

Maussion F, Scherer D, Finkelnburg R, Richters J, Yang W, Yao T (2011) WRF simulation of a precipitation event over the Tibetan Plateau, China - an assessment using remote sensing and ground observations. Hydrol Earth Syst Sci 15:1795-1817. https://doi. org/10.5194/hess-15-1795-2011

Morrison HCJA, Curry JA, Khvorostyanov VI (2005) A new doublemoment microphysics parameterization for application in cloud and climate models. Part I: description. J Atmos Sci 62:16651677. https://doi.org/10.1175/JAS3446.1

Müller MD, Scherer D (2005) A grid-and subgrid-scale radiation parameterization of topographic effects for mesoscale weather forecast models. Mon Weather Rev 133:1431-1442. https://doi. org/10.1175/MWR2927.1

Nan S, Zhao P, Yang S, Chen J (2009) Springtime tropospheric temperature over the Tibetan Plateau and evolutions of the tropical Pacific SST. J Geophys Res Atmos. https://doi.org/10.1029/2008j d011559

Neupane N, Cook KH (2013) A nonlinear response of Sahel rainfall to Atlantic warming. J Clim 26:7080-7096. https://doi.org/10. 1175/JCLI-D-12-00475.1

Olauson J (2018) ERA5: the new champion of wind power modelling? Renew Energy 126:322-331

Ou T, Chen D, Chen X, Lin C, Yang K, Lai H, Zhang F (2020) Simulation of summer precipitation diurnal cycles over the Tibetan Plateau at the gray-zone grid spacing for cumulus parameterization. Clim Dyn 54:3525-3539. https://doi.org/10.1007/ s00382-020-05181-X

Pan Y, Shen Y, Yu JJ, Zhao P (2012) Analysis of the combined gaugesatellite hourly precipitation over China based on the OI technique. Acta Meteorol Sin 70:1381-1389

Pereira Filho AJ, Carbone RE, Janowiak JE, Arkin P, Joyce R, Hallak R, Ramos CG (2010) Satellite rainfall estimates over south america-possible applicability to the water management of large watersheds 1. JAWRA J Am Water Resour Assoc 46:344-360. https://doi.org/10.1111/j.1752-1688.2009.00406.x

Pleim JE, Xiu A (1995) Development and testing of a surface flux and planetary boundary layer model for application in mesoscale models. J Appl Meteorol 34:16-32. https://doi.org/10.1175/ 1520-0450-34.1.16

Pleim JE (2006) A simple, efficient solution of flux-profile relationships in the atmospheric surface layer. J Appl Meteorol Clim 45:341-347

Pleim JE (2007) A combined local and nonlocal closure model for the atmospheric boundary layer. Part I: model description and testing. J Appl Meteorol Climatol 46:1383-1395. https://doi.org/ 10.1175/JAM2539.1

Prein AF, Holland GJ, Rasmussen RM, Done J, Ikeda K, Clark MP, Liu CH (2013) Importance of regional climate model grid spacing for the simulation of heavy precipitation in the Colorado headwaters. J Clim 26:4848-4857. https://doi.org/10.1175/jcli-d-12-00727.1

Prein AF, Liu C, Ikeda K, Bullock R, Rasmussen RM, Holland GJ, Clark M (2017) Simulating North American mesoscale convective systems with a convection-permitting climate model. Clim Dyn. https://doi.org/10.1007/s00382-017-3993-2

Prein AF, Rasmussen R, Castro CL, Dai A, Minder J (2020) Special issue: advances in convection-permitting climate modeling. Clim Dyn 55:1-2. https://doi.org/10.1007/s00382-020-05240-3
Randel WJ, Smith AK, Wu F, Zou C-Z, Qian H (2016) Stratospheric temperature trends over 1979-2015 derived from combined SSU, MLS, and SABER satellite observations. J Clim 29:4843-4859. https://doi.org/10.1175/JCLI-D-15-0629.1

Rasmussen R, Ikeda K, Liu C, Gochis D, Clark M, Dai A et al (2014) Climate change impacts on the water balance of the Colorado headwaters: high-resolution regional climate model simulations. J Hydrometeorol 15:1091-1116. https://doi.org/10.1175/ jhm-d-13-0118.1

Satoh M, Kitao Y (2013) Numerical examination of the diurnal variation of summer precipitation over southern China. SOLA 9:129-133. https://doi.org/10.2151/sola.2013-029

Scaff L, Prein AF, Li Y et al (2020) Simulating the convective precipitation diurnal cycle in North America's current and future climate. Clim Dyn 55:369-382. https://doi.org/10.1007/ s00382-019-04754-9

Shen Y, Xiong A, Wang Y, Xie P (2010) Performance of high-resolution satellite precipitation products over China. J Geophys Res Atmos. https://doi.org/10.1029/2009JD012097

Shen Y, Pan Y, Yu J, Zhao P, Zhou Z (2013) Quality assessment of hourly merged precipitation product over China. Trans Atmos Sci 36:37-46

Shen Y, Zhao P, Pan Y, Yu J (2014) A high spatiotemporal gaugesatellite merged precipitation analysis over China. J Geophys Res 119:3063-3075. https://doi.org/10.1002/2013JD020686

Shi Y, Gao X, Zhang D, Giorgi F (2011) Climate change over the Yarlung Zangbo-Brahmaputra River Basin in the 21st century as simulated by a high resolution regional climate model. Quatern Int 244:159-168. https://doi.org/10.1016/j.quaint.2011.01. 041

Singh P, Nakamura K (2009) Diurnal variation in summer precipitation over the central Tibetan Plateau. J Geophys Res Atmos. https:// doi.org/10.1029/2009jd011788

Skamarock WC, Klemp JB, Dudhia J, Gill DO, Barker DM, Wang W, Powers JG (2005) A description of the advanced research WRF version 2 (No. NCAR/TN-468+ STR). National Center For Atmospheric Research Boulder Co Mesoscale and Microscale Meteorology Div

Taylor KE (2001) Summarizing multiple aspects of model performance in a single diagram. J Geophys Res Atmos 106:7183-7192. https://doi.org/10.1029/2000jd900719

Tian B, Held IM, Lau NC, Soden BJ (2005) Diurnal cycle of summertime deep convection over North America: a satellite perspective. J Geophys Res Atmos. https://doi.org/10.1029/2004jd005275

Ueno K, Sugimoto S, Koike T, Tsutsui H, Xu X (2011) Generation processes of mesoscale convective systems following midlatitude troughs around the Sichuan Basin. J Geophys Res Atmos. https:// doi.org/10.1029/2009jd013780

Wang WC, Gong W, Wei H (2000) A regional model simulation of the 1991 severe precipitation event over the Yangtze-Huai River Valley. Part I: precipitation and circulation statistics. J Clim 13:74-92. https://doi.org/10.1175/1520-0442(2000)013\% 3c0074:armsot\%3e2.0.co;2

Wang X, Pang G, Yang M (2018) Precipitation over the Tibetan Plateau during recent decades: a review based on observations and simulations. Int J Climatol 38:1116-1131. https://doi.org/10. 1002/joc.5246

Wang X, Yang M, Wan G, Chen X, Pang G (2013) Qinghai-Xizang (Tibetan) Plateau climate simulation using the regional climate model RegCM3. Clim Res 57:173-186

Weisman ML, Skamarock WC, Klemp JB (1997) The resolution dependence of explicitly modeled convective systems. Mon Weather Rev 125:527-548. https://doi.org/10.1175/15200493(1997)125\%3c0527:trdoem\%3e2.0.co;2

Weisman ML, Davis C, Wang W, Manning KW, Klemp JB (2008) Experiences with 0-36-h explicit convective forecasts with the 
WRF-ARW model. Weather Forecast 23:407-437. https://doi. org/10.1175/2007WAF2007005.1

Wu G, Liu Y, He B, Bao Q, Duan A, Jin F (2012) Thermal controls on the Asian summer monsoon. Sci Rep 2:404. https://doi.org/ 10.1038/srep00404

Wu Y, Huang A, Huang D, Chen F, Yang B, Zhou Y, Fang D, Zhang L, Wen L (2018) Diurnal variations of summer precipitation over the regions east to Tibetan Plateau. Clim Dyn 51:4287-4307. https://doi.org/10.1007/s00382-017-4042-x

Xue M, Luo X, Zhu K, Sun Z, Fei J (2018) The controlling role of boundary layer inertial oscillations in Meiyu frontal precipitation and its diurnal cycles over China. J Geophys Res Atmos 123:5090-5115. https://doi.org/10.1029/2018JD028368

Yang B, Zhou Y, Zhang Y, Huang A, Qian Y, Zhang L (2018) Simulated precipitation diurnal cycles over East Asia using different CAPE-based convective closure schemes in WRF model. Clim Dyn 50:1639-1658. https://doi.org/10.1007/s00382-017-3712-Z

Yang B, Wang M, Zhang GJ, Guo Z, Qian Y, Huang A, Zhang Y (2020) Simulated precipitation diurnal variation with a deep convective closure subject to shallow convection in Community Atmosphere Model version 5 coupled with CLUBB. J Adv Model Earth Syst 11:e2020MS002050. https://doi.org/10.1029/2020MS002050

Yin S, Chen D, Xie Y (2009) Diurnal variations of precipitation during the warm season over China. Int J Climatol J R Meteorol Soc 29:1154-1170. https://doi.org/10.1002/joc. 1758

Yu J, Shen Y, Pan Y, Zhao P, Zhou ZJ (2013) Improvement of satellitebased precipitation estimates over China based on probability density function matching method. J Appl Meteorol 24:544-553

Yu R, Wang B, Zhou T (2004) Climate effects of the deep continental stratus clouds generated by the Tibetan Plateau. J Clim 17:27022713. https://doi.org/10.1175/1520-0442(2004)017\%3c2702: CEOTDC\%3e2.0.CO;2

Yu R, Li J, Chen H, Yuan W (2014) Progress in studies of the precipitation diurnal variation over contiguous China. J Meteorol Res 28:877-902. https://doi.org/10.1007/s13351-014-3272-7

Yu R, Xu Y, Zhou T, Li J (2007) Relation between rainfall duration and diurnal variation in the warm season precipitation over central eastern China. Geophys Res Lett 34:L13703. https://doi.org/10. 1029/2007GL030315

Yu R, Yuan W, Li J, Fu Y (2009) Diurnal phase of late-night against late-afternoon of stratiform and convective precipitation in summer southern contiguous China. Clim Dyn 35:567-576. https:// doi.org/10.1007/s00382-009-0568-x

Yuan W, Yu R, Chen H, Li J, Zhang M (2010) Subseasonal characteristics of diurnal variation in summer monsoon rainfall over Central Eastern China. J Clim 23:6684-6695. https://doi.org/10. 1175/2010JCLI3805.1

Yuan W, Li J, Chen H, Yu R (2011) Intercomparison of summer rainfall diurnal features between station rain gauge data and TRMM 3B42 product over central eastern China. Int J Climatol 32:16901696. https://doi.org/10.1002/joc. 2384
Yue S, Wang B, Yang K, Xie Z, Lu H, He J (2020) Mechanisms of the decadal variability of monsoon rainfall in the southern Tibetan Plateau. Environ Res Lett 16:014011

Zhang D, Gao X, Bai H, Li D (2005) Simulation of climate over Qinghai-Xizang Plateau utilizing RegCM3 (Chinese with English abstract). Plateau Meteorol 24:714-720

Zhang Y, Yu R, Li J, Yuan W, Zhang M (2013) Dynamic and thermodynamic relations of distinctive stratus clouds on the lee side of the Tibetan plateau in the cold season. J Clim 26:8378-8391

Zhang Y, Huang A, Zhu X (2006) Parameterization of the thermal impacts of sub-grid orography on numerical modeling of the surface energy budget over East Asia. Theor Appl Climatol 86:201-214. https://doi.org/10.1007/s00704-005-0209-1

Zhang Y, Xue M, Zhu K, Zhou B (2019) What is the main cause of diurnal variation and nocturnal peak of summer precipitation in Sichuan Basin, China? The key role of boundary layer lowlevel jet inertial oscillations. J Geophys Res Atmos 124:2643-2664. https://doi.org/10.1029/2018JD029834

Zhao Y, Huang A, Kan M et al (2020) Characteristics of hourly extreme precipitation along the Yangtze River Basin, China during Warm Season. Sci Rep 10:5613. https://doi.org/10.1038/ s41598-020-62535-5

Zheng Y, Xue M, Li B, Chen J, Tao Z (2016) Spatial characteristics of extreme rainfall over China with hourly through 24-hour accumulation periods based on national-level hourly rain gauge data. Adv Atmos Sci 33:1218-1232. https://doi.org/10.1007/ s00376-016-6128-5

Zhou T, Yu R, Chen H, Dai A, Pan Y (2008) Summer precipitation frequency, intensity, and diurnal cycle over China: a comparison of satellite data with rain gauge observations. J Clim 21:3997-4010. https://doi.org/10.1175/2008JCLI2028.1

Zhou X, Zhao P, Chen J, Chen L, Li W (2009) Impacts of thermodynamic processes over the Tibetan Plateau on the Northern Hemispheric climate. Sci China Ser D Earth Sci 52:1679-1693. https://doi.org/10.1007/s11430-009-0194-9

Zhu K, Xue M (2016) Evaluation of WRF-based convection-permitting multi-physics ensemble forecasts over China for an extreme rainfall event on 21 July 2012 in Beijing. Adv Atmos Sci 33:12401258. https://doi.org/10.1007/s00376-016-6202-Z

Zhu K, Xue M, Zhou B, Zhao K, Sun Z, Fu P, Zheng Y, Zhang X, Meng Q (2018) Evaluation of real-time convection-permitting precipitation forecasts in China during the 2013-2014 summer season. J Geophys Res Atmos 123:1037-1064. https://doi.org/ 10.1002/2017JD027445

Publisher's Note Springer Nature remains neutral with regard to jurisdictional claims in published maps and institutional affiliations. 